\title{
A rapid method to derive horizontal distributions of trace gases and aerosols near the surface using multi-axis differential optical absorption spectroscopy
}

\author{
Y. Wang ${ }^{1}$, A. Li ${ }^{1}$, P. H. Xie ${ }^{1}$, T. Wagner ${ }^{2}$, H. Chen ${ }^{1}$, W. Q. Liu ${ }^{1}$, and J. G. Liu ${ }^{1}$ \\ ${ }^{1}$ Anhui Institute of Optics and Fine Mechanics, Chinese Academy of Sciences, Hefei, China \\ ${ }^{2}$ Max Planck Institute for Chemistry, Hahn-Meitner-Weg 1, 55128 Mainz, Germany \\ Correspondence to: T. Wagner (thomas.wagner@mpic.de) and P. H. Xie (phxie@aiofm.ac.cn) \\ Received: 17 June 2013 - Published in Atmos. Meas. Tech. Discuss.: 4 September 2013 \\ Revised: 26 March 2014 - Accepted: 27 March 2014 - Published: 11 June 2014
}

\begin{abstract}
We apply a novel experimental procedure for the rapid measurement of the average volume mixing ratios (VMRs) and horizontal distributions of trace gases such as $\mathrm{NO}_{2}, \mathrm{SO}_{2}$, and $\mathrm{HCHO}$ in the boundary layer, which was recently suggested by Sinreich et al. (2013). The method is based on two-dimensional scanning multi-axis differential optical absorption spectroscopy (MAX-DOAS). It makes use of two facts (Sinreich et al., 2013): first, the light path for observations at $1^{\circ}$ elevation angle traverses mainly air masses located close to the ground (typically $<200 \mathrm{~m}$ ); second, the light path length can be calculated using the simultaneous measured absorption of the oxygen dimer $\mathrm{O}_{4}$. Thus, the average value of the trace gas VMR in the atmospheric layer between the surface and the particular altitude, for which this observation was sensitive, can be calculated. Compared to the originally proposed method, we introduce several important modifications and improvements: We apply the method only to measurements at $1^{\circ}$ elevation angle (besides zenith view), for which the uncertainties of the retrieved values of the VMRs and surface extinctions are especially small. Using only $1^{\circ}$ elevation angle for off-axis observation also allows an increased temporal resolution. We determine (and apply) correction factors (and their uncertainties) directly as function of the measured $\mathrm{O}_{4}$ absorption. Finally, the method is extended to trace gases analysed at other wavelengths and also to the retrieval of aerosol extinction. Depending on atmospheric visibility, the typical uncertainty of the results ranges from about $20 \%$ to $30 \%$.
\end{abstract}

We apply the rapid method to observations of a newlydeveloped ground-based multifunctional passive differential optical absorption spectroscopy (GM-DOAS) instrument in the north-west outskirts near Hefei in China. We report $\mathrm{NO}_{2}$, $\mathrm{SO}_{2}$, and HCHO VMRs and aerosol extinction for four azimuth angles and compare these results with those from simultaneous long-path DOAS observations. Good agreement is found (squares of the correlation coefficients for $\mathrm{NO}_{2}$, $\mathrm{SO}_{2}$, and $\mathrm{HCHO}$ were $0.92,0.85$, and 0.60 , respectively), verifying the reliability of this novel method. Similar agreement is found for the comparison of the aerosol extinction with results from visibility meters. Future studies may conduct measurements using a larger number of azimuth angles to increase the spatial resolution.

\section{Introduction}

Nitrogen dioxide $\left(\mathrm{NO}_{2}\right)$, sulfur dioxide $\left(\mathrm{SO}_{2}\right)$, and formaldehyde (HCHO) are important atmospheric constituents which play crucial roles in tropospheric chemistry (Crutzen, 1979; Lurmann et al., 1992; Ho et al., 2002; Hellén et al., 2004; Smith et al., 2011). $\mathrm{NO}_{2}$ partly controls lower atmospheric oxidizing capacity. $\mathrm{HCHO}$ is important for estimating photochemical processes. Sulfate aerosols formed by $\mathrm{SO}_{2}$ are sources of inhalable particles. Presently, anthropogenic emissions from traffic, industry, and biomass burning have significantly increased the concentrations of these gases in the boundary layer directly affecting air quality and human health (Environmental Protection Agency, 1998; Seinfeld 
and Pandis, 1998). To understand the influences of these gases on atmospheric chemistry processes and to formulate effective strategies for pollution regulation, studying the spatial and temporal distribution of these gases is necessary.

The horizontal distribution of trace gases in the boundary layer is usually inhomogeneous near strong emission sources. Investigating the horizontal distribution of trace gases is useful for atmospheric chemistry research and environment pollution treatment. Passive differential optical absorption spectroscopy (DOAS) (Platt and Stutz, 2008) is a technique widely used to measure the distribution and variation of trace gases such as $\mathrm{NO}_{2}, \mathrm{SO}_{2}$, and $\mathrm{HCHO}$. Satellite DOAS has also been widely used to study the global distribution of trace gases (Bovensmann et al., 1999; Burrows et al., 1999, 2011; Wagner et al., 2008; De Smedt, 2010). However, this technique focuses on large-scale horizontal distribution. Mobile DOAS is useful for studying horizontal distribution (Johansson et al., 2008, 2009; Wagner et al., 2010; Wu et al., 2013) but requires comparatively large efforts. Tomographic target light scattering (TOTAL) DOAS (Frins et al., 2006, 2008; Wang et al., 2012) is a novel method for studying high spatial resolution near-surface distributions of trace gases. However, the application of TOTAL DOAS relies on the availability of well-suited targets. Furthermore, the directions of measurement cannot be chosen freely.

Multi-Axis- (MAX-) DOAS is an inexpensive tool for measuring the tropospheric vertical distribution of trace gases. (Hönninger et al., 2004; Bobrowski et al., 2003; Wittrock et al., 2004; Heckel et al., 2005; Pikelnaya et al., 2007; Sinreich et al., 2007; Theys et al., 2007; Clemer et al., 2009, 2010; Vlemmix et al., 2010, 2011; Frieß et al., 2011; Irie et al., 2011; Wagner et al., 2011; Li et al., 2013; Yilmaz, 2012). Concentration profiles of trace gases and aerosol extinction in the boundary layer can be derived from MAX-DOAS observations using different inversion techniques, e.g. the optimal estimation method (Frieß et al., 2006, 2011; Yilmaz, 2012) or a look-up table approach (Li et al., 2010, 2013; Wagner et al., 2011). These methods usually apply a twostep procedure and are rather time consuming.

A novel retrieval technique based on ground-based MAXDOAS observations was recently proposed by Sinreich et al. (2013): The effective light path length in the boundary layer determined by the $\mathrm{O}_{4}$ differential slant column density (dSCD) for low elevation angles is used to convert the dSCD of trace gases into near-surface mixing ratios. Compared to a full profile inversion from MAX-DOAS observations, this method is much simpler and faster, but can also be subject to larger uncertainties in specific situations (see below). In our study we use this new retrieval technique, but apply several important modifications:

a. We only use measurements at $1^{\circ}$ elevation angle. For such low elevation angles the influence of the relative profile shape of the trace gases or aerosols on the retrieved results is smaller than for higher elevation angles (and in most cases the correction factors are closer to unity). The restriction to only $1^{\circ}$ elevation angle (besides zenith view) also leads to a higher temporal and spatial resolution.

b. We parameterize the calculated correction factors (and their uncertainties) as a function of the simultaneously modelled differential air mass factors (dAMF) of $\mathrm{O}_{4}$ (Martin et al., 2002; Eskes and Boursma, 2003; Frins et al., 2006; Richter and Wagner, 2011). Using this parameterization, appropriate correction factors for a given measurement can be directly determined according to the measured $\mathrm{O}_{4}$ dSCDs (after conversion to $\mathrm{O}_{4} \mathrm{dAMF}$, see Sect. 2).

c. We develop a method to extrapolate the effective light path lengths from the wavelength of the $\mathrm{O}_{4}$ measurement (here $360 \mathrm{~nm}$ ) to other wavelengths. This allows the extension of the method to trace gases which are retrieved at wavelengths different from those of the $\mathrm{O}_{4}$ absorptions (like e.g. $\mathrm{SO}_{2}$ ).

d. In addition to the trace gas VMRs close to the surface, we also retrieve the near-surface aerosol extinction.

We apply the rapid method to a newly developed twodimensional (2-D) MAX-DOAS instrument, which can point to any azimuth and elevation angle. Using the new technique, information on the horizontal distribution of near-surface trace gas VMRs close to the experimental site with a time resolution of approximately 2 min can be obtained. For each azimuth angle, after each spectrum measured at $1^{\circ}$ elevation angle, an observation at $90^{\circ}$ was made to record a Fraunhofer reference spectrum. Given that the light path for observations at $1^{\circ}$ elevation angle is located near the ground (typically $<200 \mathrm{~m}$ ) and its length can be calculated using the simultaneous measured absorption of the stable oxygen dimer $\mathrm{O}_{4}$, the average volume mixing ratios (VMR) of the trace gases near the ground can be calculated.

In this paper, we first discuss the details of the method using the full-spherical radiative transfer model (RTM) SCIATRAN 2.2 (Rozanov, 2005). Then, we present results of rapid $\mathrm{NO}_{2}, \mathrm{SO}_{2}$, and $\mathrm{HCHO}$ VMR measurements for four azimuth angles in the north-west outskirts near Hefei in China using ground-based multifunctional DOAS (GM-DOAS). The accuracy of the rapid MAX-DOAS method is discussed in comparison with long-path (LP) DOAS (Qin et al., 2006). Furthermore, the horizontal distributions of the trace gases are analysed based on the results for the four azimuth angles. Then the aerosol extinction close to the surface is determined with the rapid MAX-DOAS method and compared to the results derived from visibility meters. Finally, the error sources of the average VMR of trace gases for the rapid MAX-DOAS method are discussed. 


\section{Retrieving the average VMR of trace gases close to the surface from low elevation MAX-DOAS observations}

The direct light path along the line of sight for observations at a low elevation angle is located close to the surface. Thus, such observations are most sensitive to near-surface trace gases. The effective length of the direct light path is determined by the atmospheric visibility and thus by scattering by air molecules and aerosol particles. Since the concentration of air molecules is almost constant, the effective length of the direct path is determined by the concentration and optical properties of atmospheric aerosols. For MAX-DOAS observation, a Fraunhofer reference spectrum is needed to remove the strong Fraunhofer lines of the measured spectrum at low elevation angle. Thus for trace gases with a substantial stratospheric partial column the stratospheric absorption also cancels out, because the stratospheric light paths are almost independent of elevation angle. The application of the Fraunhofer reference spectrum further enhances the weighting of the measurement sensitivity towards the surface, because the absorptions from the atmosphere above the surface-near layers mainly cancel out.

These basic dependencies are discussed in detail in the recently published study of Sinreich et al. (2013). They also developed a parameterized algorithm to convert the measured dSCDs of $\mathrm{O}_{4}, \mathrm{NO}_{2}$, and $\mathrm{HCHO}$ at low elevation angles to box-averaged mixing ratios of $\mathrm{NO}_{2}$ and $\mathrm{HCHO}$.

As suggested by Sinreich et al. (2013), the effective light path length $(L)$ can be calculated from the retrieved $\mathrm{O}_{4}$ dSCD:

$\mathrm{L}=\frac{\mathrm{dSCD}_{\mathrm{O}_{4}}}{c_{\mathrm{O}_{4}}}=\frac{\mathrm{dAMF}_{\mathrm{O}_{4}} \cdot \mathrm{VCD}_{\mathrm{O}_{4}}}{c_{\mathrm{O}_{4}}}$.

The near-surface $\mathrm{O}_{4}$ concentration $\left(c_{\mathrm{O}_{4}}\right)$ is calculated to be $2.79 \times 10^{37}$ molecules $\mathrm{cm}^{-6}$ using local atmospheric temperature and pressure. The $\mathrm{O}_{4}$ concentration is proportional to the square of the $\mathrm{O}_{2}$ concentration (Greenblatt et al., 1990; Wagner et al., 2002). Accordingly, the $\mathrm{O}_{4} \mathrm{dSCD}$ is expressed in units of molecules $\mathrm{cm}^{-5}$.

The $\mathrm{O}_{4} \mathrm{dSCD}$ can be also expressed as the product of the $\mathrm{O}_{4}$ dAMF and the $\mathrm{O}_{4} \mathrm{VCD}$ (last term in Eq. 1). In this study for the $\mathrm{O}_{4} \mathrm{VCD}$ a fixed value of $1.19 \times 10^{43}$ molecules $\mathrm{cm}^{-5}$ was used, calculated from standard pressure and temperature profiles in May at the northern latitude of $35^{\circ}$ from the climatological database developed by MPIC Mainz (Brühl and Crutzen, 1993). No temperature dependence of the $\mathrm{O}_{4} \mathrm{ab}-$ sorption cross section (see e.g. Thalman and Volkamer, 2013) was considered. The surface elevation of the measurement site (approximately $50 \mathrm{~m}$ a.s.l.) was taken into account.

Here it should be noted that in the following, the measured $\mathrm{O}_{4}$ dSCDs are always expressed as $\mathrm{O}_{4}$ dAMF using the above mentioned value of the $\mathrm{O}_{4} \mathrm{VCD}$. This procedure allows a direct comparison between the $\mathrm{O}_{4}$ measurements and the results of the radiative transfer simulations.
It should also be noted that $L$ is not the absolute light path length for the observation at $1^{\circ}$ elevation angle, but the difference between the light path lengths for the observation at $1^{\circ}$ elevation angle and the Fraunhofer reference spectrum made in zenith direction. Note that the effective light path length derived in Eq. (1) is representative for $360 \mathrm{~nm}$ because it was derived from the $\mathrm{O}_{4}$ absorption band at $360 \mathrm{~nm}$. It can be transformed for other wavelength ranges of $340 \mathrm{~nm}$ and $310 \mathrm{~nm}$ using Eqs. (6) and (7) (see Sect. 2.1).

Using this effective light path length derived in Eq. (1), the average trace gas concentration (and from that also the VMR) near the ground can be calculated from the derived trace gas dSCD:

$\mathrm{c}=\mathrm{dSCD} / L$.

It was shown by Sinreich et al. (2013) that using this simple retrieval scheme, systematic errors are introduced, if the relative profile of the considered trace gas differs from that of $\mathrm{O}_{4}$. For atmospheric pollutants, this is generally the case: Since they are emitted mainly from sources close to the surface, their abundances are typically largest at low altitudes, but decrease rapidly with altitude, especially above the boundary layer. Sinreich et al. (2013) suggested to apply correction factors to the results derived from Eq. (2):

$\mathrm{c}_{\text {corr }}=c / f_{\text {corr }}$.

These correction factors are derived from radiative transfer simulations assuming different profiles of trace gases and aerosols (for details see Sinreich et al., 2013, and Sect. 2.2). Here it is important to note that in contrast to higher elevation angles the correction factors for an elevation angle of $1^{\circ}$ are usually closer to unity than for higher elevation angles. This indicates that the very low elevation angles are particularly well suited for the application of the simple parameterized retrieval technique. Also, the uncertainties of the correction factors for $1^{\circ}$ elevation are typically small: depending on the atmospheric visibility and the considered trace gas. They are usually between $20 \%$ and $30 \%$ (see Sect. 2.2).

\subsection{Extrapolation of the effective light path length to other wavelengths}

Considering the wavelength dependence of Rayleigh and aerosol scattering, the effective light path $L$ should systematically vary with wavelength. Since the light path length based on the $\mathrm{O}_{4}$ information is obtained at $360 \mathrm{~nm}$, it is not exactly representative for other wavelengths. Therefore, extrapolating $L$ to other wavelength ranges is an important aspect for the analysis of additional trace gases such as $\mathrm{SO}_{2}(310 \mathrm{~nm})$ and HCHO $(340 \mathrm{~nm})$. The relationships between the light path lengths at 310 and $340 \mathrm{~nm}$ to those at $360 \mathrm{~nm}$ were studied using SCIATRAN for a variety of aerosol scenarios. The aerosol types of the aerosol scenarios were classified as "urban" (single scattering albedo of 0.817 and asymmetry factor 


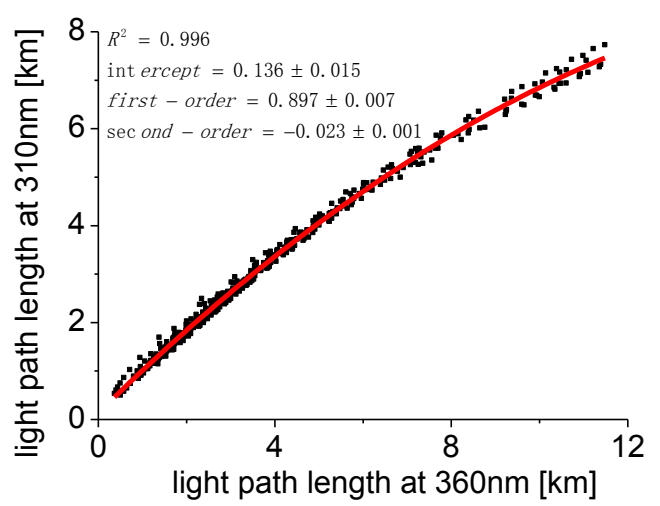

Figure 1. Scatter plot of light path lengths at $310 \mathrm{~nm}$ against light path lengths at $360 \mathrm{~nm}$ for 60 aerosol scenarios and combinations of three SZAs and RAAs. The statistical parameters derived from a second-order polynomial fitted to the simulation results are also shown.

of 0.689 at $550 \mathrm{~nm}$ ) in the boundary layer and "continental average" (single scattering albedo of 0.925 and asymmetry factor of 0.703 at $550 \mathrm{~nm}$ ) in the free troposphere based on the software package OPAC (Hess et al., 1998). Note that these aerosol particle properties are well suited for polluted sites. If this method is used in other conditions, different aerosol properties should be used. However, since the differences in wavelength considered here are rather small, the resulting deviations from the relationships determined in this study are also expected to be small.

We assumed that the aerosol profiles contain two layers, namely, the atmospheric boundary layer and the free troposphere. The layers can be described using three parameters, namely aerosol optical depth $(\tau)$, fraction $(F)$ of $\tau$ in the boundary layer, and height $(H)$ of the boundary layer ( $\mathrm{Li}$ et al., 2010). The aerosol extinction profile $E(z)$ in the range of $0 \mathrm{~km}$ to $15 \mathrm{~km}$ was assumed as follows:

$E(z)=\left\{\begin{array}{cc}\tau \cdot F / H & z \leq H \\ \beta \cdot \exp (-z / \xi) & z>H\end{array}\right.$.

Here $\beta$ is the normalizing constant for the exponential factor and can be calculated using Eq. (5)

$\beta=\frac{(1-F) \times \tau}{\xi \times\left(e^{-H / \xi}-e^{-15 \mathrm{~km} / \xi}\right)}$,

where $\xi$ is the scaling height for the aerosol in the free tropospheric layer, which was set to $5 \mathrm{~km}$. The three parameters for the 60 aerosol scenarios used are shown in Table 1.

$\mathrm{O}_{4}$ dAMF were calculated for three wavelengths $(310 \mathrm{~nm}$, $340 \mathrm{~nm}, 360 \mathrm{~nm}$ ) using RTM based on the assumed aerosol scenarios. We performed simulations for three SZAs $\left(20^{\circ}\right.$, $40^{\circ}$, and $\left.50^{\circ}\right)$ and relative azimuth angles (RAAs) $\left(30^{\circ}, 90^{\circ}\right.$, and $180^{\circ}$ ). The corresponding effective light path lengths were calculated from the modelled $\mathrm{O}_{4}$ dAMF using Eq. (1).

The light path lengths at $310 \mathrm{~nm}$ as a function of the light path lengths at $360 \mathrm{~nm}$ are plotted in Fig. 1. A second-order

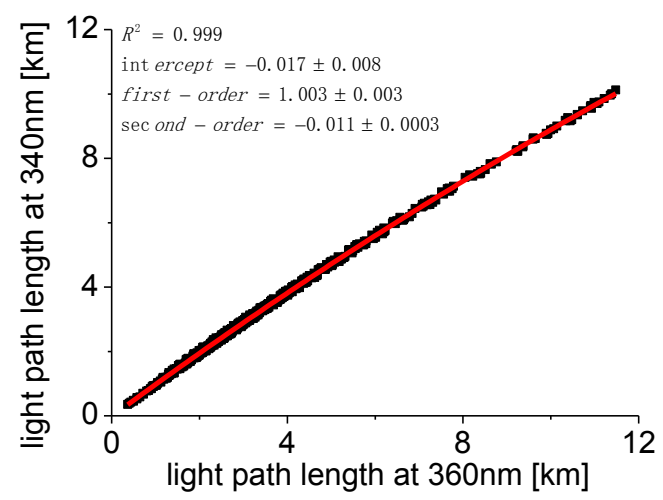

Figure 2. Scatter plot of light path lengths at $340 \mathrm{~nm}$ against light path lengths at $360 \mathrm{~nm}$ for 60 aerosol scenarios and combinations of three SZAs and RAAs. The statistical parameters derived from a second-order polynomial fitted to the simulation results are also shown.

polynomial was fitted to the simulation results with a square correlation coefficient of approximately 1 . The statistical parameters of this curve are also shown in Fig. 1. From the close relationship we conclude that the light path length at $310 \mathrm{~nm}$ $\left(L_{310}\right)(\mathrm{km})$ can be obtained from $L_{360}(\mathrm{~km})$ using the fitted polynomial:

$L_{310}=0.136+0.897 \times L_{360}-0.023 \times L_{360}^{2}$.

For HCHO, the fit curve and parameters of the light path lengths (represented as dots) at $340 \mathrm{~nm}\left(L_{340}\right)(\mathrm{km})$ against $L_{360}(\mathrm{~km})$ are shown in Fig. 2. Again, $L_{340}(\mathrm{~km})$ can be calculated from $L_{360}(\mathrm{~km})$ using the fitted polynomial:

$L_{340}=-0.017+1.003 \times L_{360}-0.011 \times L_{360}^{2}$.

Since the effective light path lengths depend on the aerosol load, also the altitude range, for which the trace gas VMR is derived by Eq. (2), depends on the aerosol load. This probed altitude range $(h)(\mathrm{km})$ can be briefly calculated from $L(\mathrm{~km})$ using the geometric approximation (Sinreich et al., 2013):

$h=L \times \sin \left(1^{\circ}\right)$.

With $\sin \left(1^{\circ}\right)=0.0175$, for typical values of $L(L<10 \mathrm{~km}$ as shown in Fig. 15), the layer height $h$ is below $200 \mathrm{~m}$.

\subsection{The influence of the topography around the observation site on the effective light path length}

So far we assumed that the path lengths are not affected by topography. However, for observations at low elevation angles, for which the light path is close to the surface, such effects might play a role. We investigate two possible effects of topography in more detail using radiative transfer simulations:

a. the effect of installing an instrument at an elevated level (e.g. on the roof of a high building). We performed radiative transfer simulations for an instrument located at 
Table 1. Parameters for 60 chosen aerosol scenarios (all combinations of these values were explored).

\begin{tabular}{ll}
\hline Parameter & Values \\
\hline Aerosol optical depth $(\tau)$ & $0.1,0.3,0.5,0.7,0.9,1.1,1.3,1.5,1.7,2.0$ \\
Fraction $(F)$ of $\tau$ in the boundary layer & 0.8 \\
Height $(H)$ of the boundary layer $(\mathrm{km})$ & $0.5,0.8,1.1,1.4,1.7,1.9$ \\
\hline
\end{tabular}

$100 \mathrm{~m}$ height above the ground. The $\mathrm{O}_{4}$ air mass factors for an elevation angle of $1^{\circ}$ differ from the respective results for an instrument located at the ground by less than $1 \%$ (see Fig. 3). Thus we conclude that the effect of the height of the instrument can be neglected.

b. the effect of mountains in the field of view at different distances. Mountains close to the observation site may block the view at low elevation angles. In such cases the effective light path length can become much shorter than without a mountain in the field of view. Moreover, the light path length derived from the $\mathrm{O}_{4}$ absorption might not be representative anymore for the determination of the trace gas mixing ratios according to Eqs. (1), (2), and (3). To quantify the effects of mountains in the field of view we simulated $\mathrm{O}_{4}$ AMFs at $310 \mathrm{~nm}, 360 \mathrm{~nm}$, and $440 \mathrm{~nm}$ for scenarios with mountains at $2 \mathrm{~km}, 5 \mathrm{~km}$, $10 \mathrm{~km}, 15 \mathrm{~km}, 20 \mathrm{~km}$, and $25 \mathrm{~km}$ distances. The results are shown in Fig. 3.

We find that the effect of mountains depends on the wavelength and aerosol load. For high AOD (>0.5) only mountains at distances shorter than $10 \mathrm{~km}$ have a substantial effect on the $\mathrm{O}_{4}$ AMF (deviation $>10 \%$ compared to the case without mountains). For low AOD $(<0.1)$ mountains at distances up to $20 \mathrm{~km}$ also become important. Thus we recommend that the MAX-DOAS observations should be made at azimuth angles, at which the field of view is free over a distance of about $20 \mathrm{~km}$. In such cases the effects of mountains can be neglected.

If the distance of mountains in the field of view is smaller, the respective details of the topography should be included in the determination of the correction factors (Sect. 2.3). If mountains are present at very short distances, the method of TOTAL-DOAS (Frins et al., 2006, 2008) might be applied in the data analysis.

For the interpretation of our measurements, topography effects can be neglected fortunately, because the surface around the observation site is flat and our MAX-DOAS instrument is located just on the 7th floor of the building, at about $35 \mathrm{~m}$.

\subsection{Calculation of correction factors}

Because of the different vertical profile shapes of $\mathrm{O}_{4}$ and the atmospheric pollutants $\left(\mathrm{NO}_{2}, \mathrm{HCHO}, \mathrm{SO}_{2}\right)$, the VMRs calculated using Eqs. (1) and (2) are usually different from the true near-surface VMRs. To correct these deviations, correction factors (Eq. 3) were suggested by Sinreich et al. (2013).
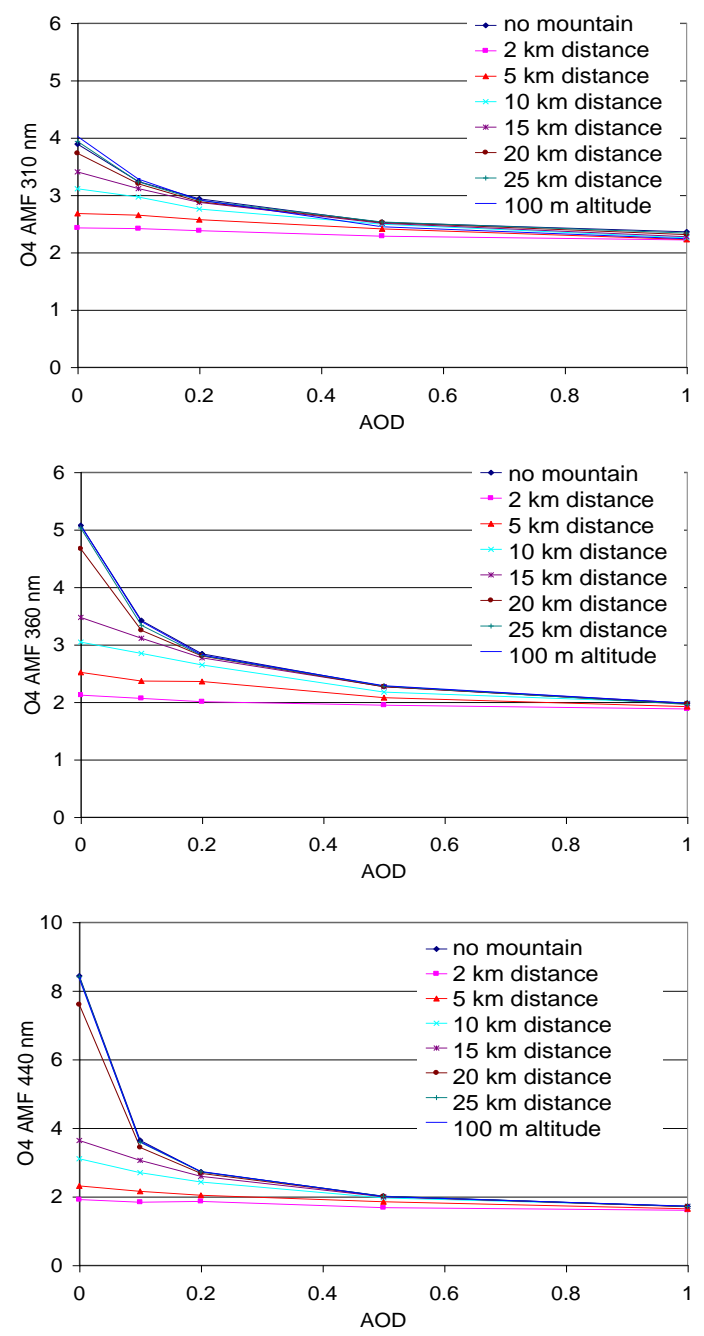

Figure 3. Simulated $\mathrm{O}_{4}$ AMFs for $1^{\circ}$ elevation angle at $310 \mathrm{~nm}$ (top), $360 \mathrm{~nm}$ (middle), and $440 \mathrm{~nm}$ (bottom) as a function of the aerosol optical depth (AOD). Results for cases with mountains in the field of view at different distances $(2 \mathrm{~km}, 5 \mathrm{~km}, 10 \mathrm{~km}, 15 \mathrm{~km}$, $20 \mathrm{~km}, 25 \mathrm{~km}$ ) are compared to a reference case without a mountain. Also, results for an instrument located at a height of $100 \mathrm{~m}$ above ground (e.g. at the roof of a high building) are shown (with no mountain). 

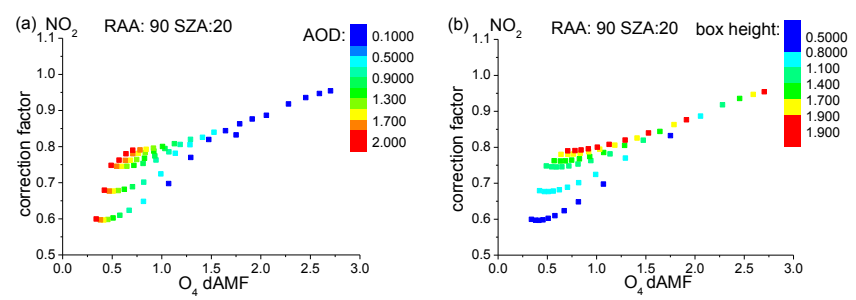

Figure 4. Correction factors for a trace gas box profile $(1 \mathrm{~km})$ as function of the $\mathrm{O}_{4}$ dAMF calculated for 60 different aerosol scenarios (see Table 1). The colours indicate the AOD (a) and aerosol layer height (b). Calculations are performed for $360 \mathrm{~nm}$ and for a RAA of $90^{\circ}$ and SZA of $20^{\circ}$.

The correction factors are derived from RTM using assumptions on the profile shapes of the trace gases and aerosols:

$f_{\text {corr }}=\frac{c_{\text {retrieved }}}{c_{\text {model }}}=\frac{\mathrm{dSCD}_{\text {model }}}{L \cdot c_{\text {model }}}$.

Here $c_{\text {retrieved }}$ is the average trace gas concentration within the probed altitude range (see Eqs. 2 and 8 ). $c_{\text {model }}$ is the assumed trace gases concentration within the trace gas layer which was used as input in the RTM. $c_{\text {retrieved }}$ is the ratio of the simulated trace gas $\mathrm{dSCD}\left(\mathrm{dSCD}_{\text {model }}\right)$ and $L$ (which is calculated from the simulated $\mathrm{O}_{4} \mathrm{dAMF}$ using Eq. 1). Note that Eq. (9) uses slightly different terms compared to Eqs. (4) and (5) in Sinreich et al. (2013): We prefer to use $c_{\text {model }}$ instead of $\frac{\mathrm{VCDNO2}}{\mathrm{PBLh}}$ because the planetary boundary layer is not always uniformly filled by atmospheric pollutants.

The uncertainties of the correction factors increase with elevation angle (see also Sinreich et al., 2013). Note that the correction factors for $310 \mathrm{~nm}$ and $340 \mathrm{~nm}$ are calculated using the modified values of $L$ based on Eqs. (6) and (7). We calculate correction factors for an elevation angle of $1^{\circ}$ at the wavelengths used in this study $(310 \mathrm{~nm}, 340 \mathrm{~nm}, 360 \mathrm{~nm})$.

For the trace gases we assume homogenous box layers with altitudes of $0.5 \mathrm{~km}, 1 \mathrm{~km}$, and $2 \mathrm{~km}$ (see Sinreich et al., 2013). For the aerosols, we use the profiles introduced in Sect. 2.1 (see Table 1). Figure 4 shows the dependence of the correction factors for a fixed trace gas profile $(1 \mathrm{~km}$ box profile) on the different aerosol scenarios. The calculations are performed for $360 \mathrm{~nm}$ and for a RAA of $90^{\circ}$ and SZA of $20^{\circ}$. The correction factors are plotted as a function of the $\mathrm{O}_{4}$ dAMF which is also derived from the RTM. The parameterization of the correction factors as function of the $\mathrm{O}_{4} \mathrm{dAMF}$ is very important, because appropriate correction factors for a given measurement can be directly determined according to the measured $\mathrm{O}_{4}$ dAMF.

The results shown in Fig. 4a indicate that the uncertainty of the correction factors caused by variations of the aerosol profile systematically increases with increasing AOD (decreasing atmospheric visibility). The results in Fig. $4 \mathrm{~b}$ indicate that the variation of aerosol layer heights causes the strongest variation of the correction factors.

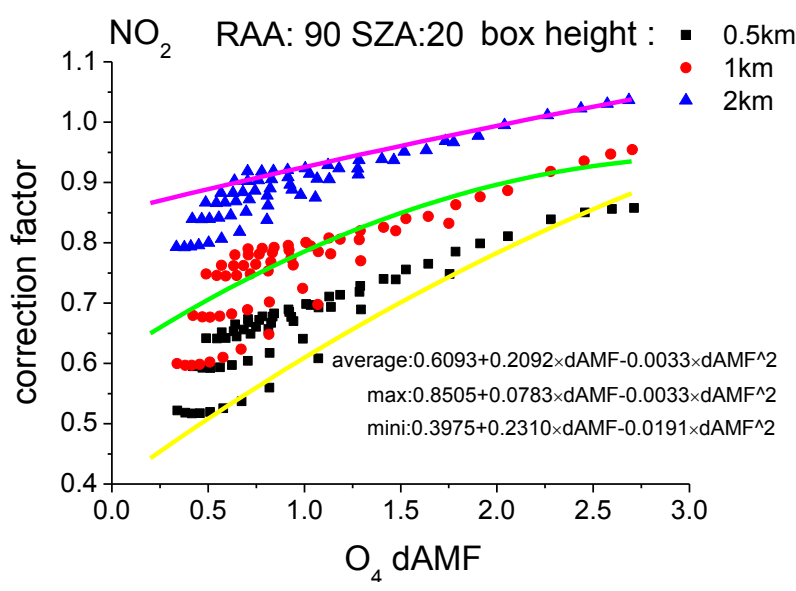

Figure 5. Correction factors for trace gas box profiles of $0.5 \mathrm{~km}$, $1 \mathrm{~km}$, and $2 \mathrm{~km}$ as well as for the 60 aerosol scenarios (Table 1) as function of the $\mathrm{O}_{4} \mathrm{dAMF}$. The green line indicates the average fitted polynomial, the magenta and yellow lines indicate polynomial fits to the maxima and minima, respectively. Calculations are performed for $360 \mathrm{~nm}$ and for a RAA of $90^{\circ}$ and SZA of $20^{\circ}$.

The variation of the trace gas profiles also has an influence on the correction factors. Like in Sinreich et al. (2013) we assume box profiles of $0.5 \mathrm{~km}, 1 \mathrm{~km}$, and $2 \mathrm{~km}$ for the trace gases. Although for individual observations the true trace gas profiles might be substantially different from such box profiles, the selected trace gas profiles are probably largely representative for the profiles of atmospheric pollutants.

Figure 5 shows the correction factors for the different trace gas layer heights including the variations caused by the different aerosol profiles (as shown in Fig. 4). The results indicate that the trace gas profiles typically have the strongest influence on the correction factors. Because both the profiles of the trace gases and aerosols are usually unknown for actual measurements, we calculate mean values of the correction factors for all combinations of trace gas and aerosol profiles as function of the $\mathrm{O}_{4}$ dAMF (second order polynomial, green line in Fig. 5). This polynomial can be used as correction factor based on the measured $\mathrm{O}_{4} \mathrm{dAMF}$. In addition, the maximum and minimum values of the correction factors as function of the $\mathrm{O}_{4}$ dAMF are also determined (using a polynomial fit to the minimum or maximum values in selected $\mathrm{O}_{4}$ dAMF bins). From these fitted polynomials (magenta and yellow lines in Fig. 5) the uncertainty of the average correction factors can be quantified. Here it should be noted that these uncertainties are only valid for the assumed range of trace gas and aerosol profiles. Although these assumptions are probably representative for most situations, in individual cases the actual profiles might be very different. Thus the uncertainties provided by the maximum and minimum values do not represent the true error for a given measurement, but can only provide a lower limit of the measurement error under the assumption that the true aerosol and trace gas profiles 

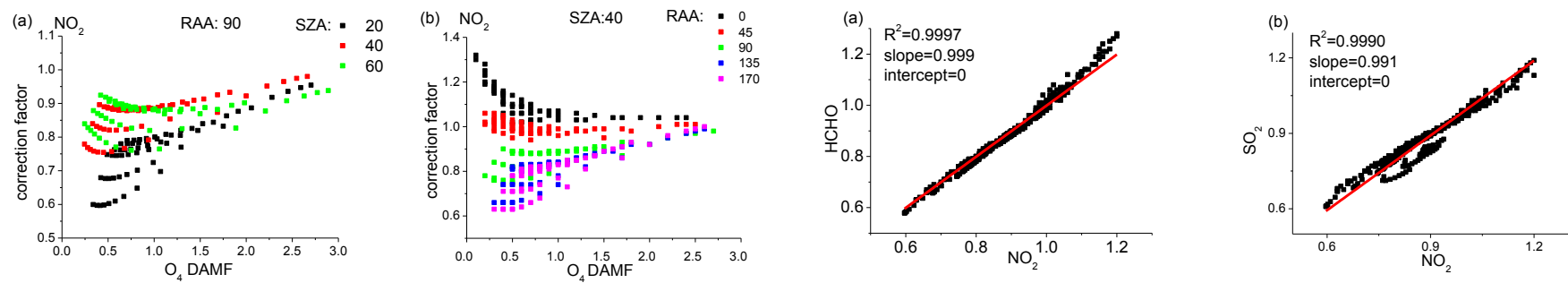

Figure 6. Correction factors for a trace gas box profile $(1 \mathrm{~km})$ as function of the $\mathrm{O}_{4}$ dAMF (a) for RAA of 90 and SZAs of $20^{\circ}, 40^{\circ}$, and $60^{\circ}$, (b) for SZA of 40 and RAAs of $0^{\circ}, 45^{\circ}, 90^{\circ}, 135^{\circ}$, and $180^{\circ}$.
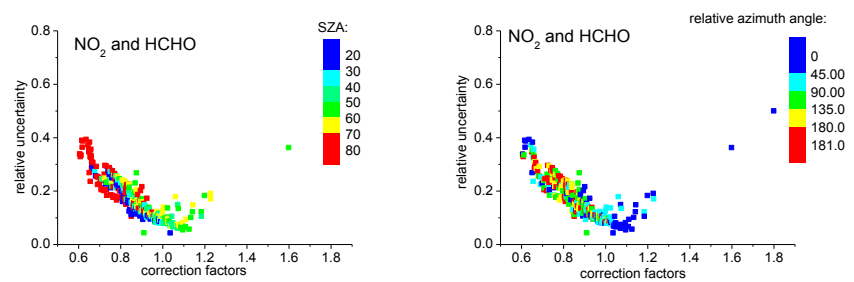

Figure 7. Relative uncertainty of the correction factor for all combinations of profiles, SZA and RAA. The colours indicate either the SZA (left) or the RAA (right). Similar results are also found for $\mathrm{SO}_{2}$ (not shown).

are within the range assumed for the radiative transfer simulations.

In addition to the dependence on the trace gas and aerosol profiles, the correction factors also systematically depend on the viewing geometry (RAA and SZA). As shown in Figs. 6 and 7 , these dependencies can become rather large. However, in contrast to the trace gas and aerosol profiles, the viewing geometry for a given measurement is exactly known and can be taken into account in the calculation of the correction factors. In Fig. 7 the relative uncertainties of the correction factors are plotted against the corresponding correction factors. The smallest uncertainties are found for correction factors close to unity. In addition, it is found that the uncertainties are especially large for specific observation geometries, especially for SZA $>70^{\circ}$ and for RAA $<50^{\circ}$. Such measurement conditions should be avoided when applying the proposed method.

In this study correction factors are calculated following two different strategies:

a. Average, minimum and maximum correction factors (as function of the $\mathrm{O}_{4}$ dAMF, see Fig. 5) are calculated for a large number of combinations of SZA and RAA. These results constitute a universal database, which can be used to correct any (future) measurements using our parameterized technique. The coefficients of the fitted polynomials (average, minimum, and maximum correction factors as function of the $\mathrm{O}_{4}$ dAMF) for all combinations of RAAs of $0^{\circ}, 45^{\circ}, 90^{\circ}, 135^{\circ}$, and $180^{\circ}$ and

Figure 8. Correlations of correction factors for the $\mathrm{HCHO}$ analysis at $340 \mathrm{~nm}$ (a) and the $\mathrm{SO}_{2}$ analysis at $310 \mathrm{~nm}$ (b) versus those for $\mathrm{NO}_{2}$ at $360 \mathrm{~nm}$.

SZAs of $20^{\circ}, 30^{\circ}, 40^{\circ}, 50^{\circ}, 60^{\circ}, 70^{\circ}$, and $80^{\circ}$ are given in the Supplement.

b. In order to provide correction factors for the measurements in this study, correction factors as function of the $\mathrm{O}_{4} \mathrm{dAMF}$ are calculated for the each specific combination of SZA and RAA based on the exact time of each measurement. These correction factors (and the respective maxima and minima) according to the measured $\mathrm{O}_{4}$ dAMF of the selected measurement are used to calculate the trace gas VMRs and the associated uncertainties (Eq. 3).

Since $\mathrm{HCHO}$ and $\mathrm{SO}_{2}$ are analysed in different wavelength ranges, appropriate correction factors for these wavelengths were also calculated. In Fig. 8 the relationships between the correction factors for $310 \mathrm{~nm}\left(\mathrm{SO}_{2}\right)$ and $340 \mathrm{~nm}$ $(\mathrm{HCHO})$ and those for $360 \mathrm{~nm}\left(\mathrm{NO}_{2}\right)$ are shown. We find that the $\mathrm{HCHO}$ correction factors are very similar to those for $\mathrm{NO}_{2}$, thus the $\mathrm{NO}_{2}$ correction factors can also be used to correct the HCHO VMRs. In contrast, the correction factors for $\mathrm{SO}_{2}$ are rather different from those for $\mathrm{NO}_{2}$, particularly for $\mathrm{NO}_{2}$ correction factors between 0.8 and 1.1 (Fig. 8). So $\mathrm{SO}_{2}$ correction factors should be calculated and applied separately.

We also investigated the influence of the surface albedo on the correction factors. In addition to the value of 0.05 , which was used as a standard value in this study, we also calculated correction factors for surface albedos of 0.03 and 0.1 . We found that over the entire range of parameters used in this study, the differences to the correction factors for an albedo of 0.05 are $<2 \%$. So we conclude that the correction factors are almost insensitive to surface albedo. Here it should be noted that this conclusion is probably not valid for exceptionally high values of the surface albedo like e.g. over snow and ice.

\section{Instrument and experiment strategy}

\subsection{The GM-DOAS instrument}

A new ground-based multifunctional DOAS (GM-DOAS) instrument, which has many optional operating patterns, was 

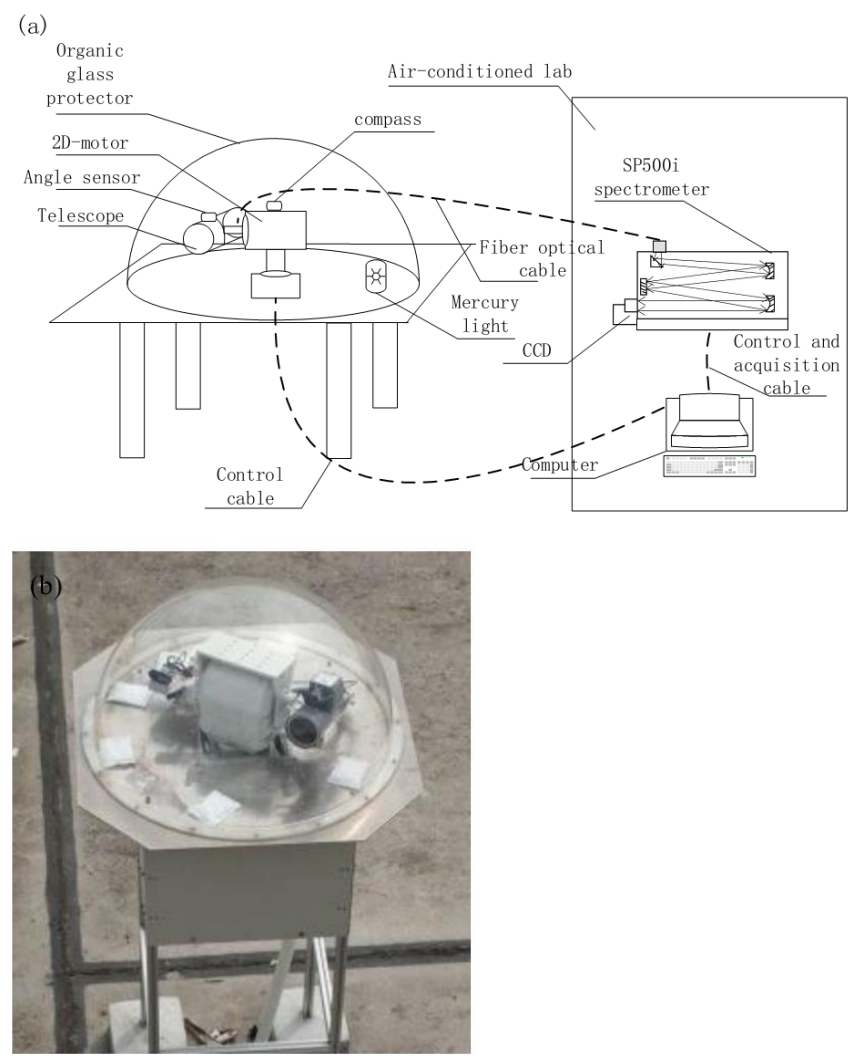

Figure 9. Schematic drawing (a) and photograph (b) of the GMDOAS instrument.

developed by our group (Fig. 9). The instrument includes a quartz telescope (field of view angle of $0.2^{\circ}$ ) with an ultraviolet-anti-reflection coating. The telescope is carried by two motors, which are located outdoors on an elevated platform to collect scattered sunlight. The motors allow two dimensional pointing of the telescope to any direction with a precision of $0.05^{\circ}$ based on the feedback of the electronic tilt sensor, with a precision of $0.01^{\circ}$. The light is focused on a $10 \mathrm{~m}$ fiber bundle consisting of $7 \times 200 \mu \mathrm{m}$ silica fibers. The end of the fiber bundle is directed to the entrance slit (with $200 \mu \mathrm{m}$ width) of the spectrometer. The spectrometer (Princeton Instrument Acton SP500i Imaging Czerny-Turner spectrometer) has 600 grooves $\mathrm{mm}^{-1}$ grating ( $300 \mathrm{~nm}$ blaze angle and $83 \mathrm{~nm}$ range) and a charge-coupled device (CCD) camera (back-illuminated 2-D CCD detector, $2048 \times 512$ pixels). The spectrometer is cooled to $-50^{\circ} \mathrm{C}$ to reduce dark current. The computer is placed indoors in an air-conditioned lab. The data of the imaging channels are binned to reduce random noise. A background spectrum is obtained by closing the shutter in front of the slit. This background spectrum uses the same integration time and number of scans as the latest measured spectrum. Thus, the background spectrum is representative for the respective offset and dark current of the detector. The background spectrum is subtracted from the measured spectrum allowing the correction of dark and offset

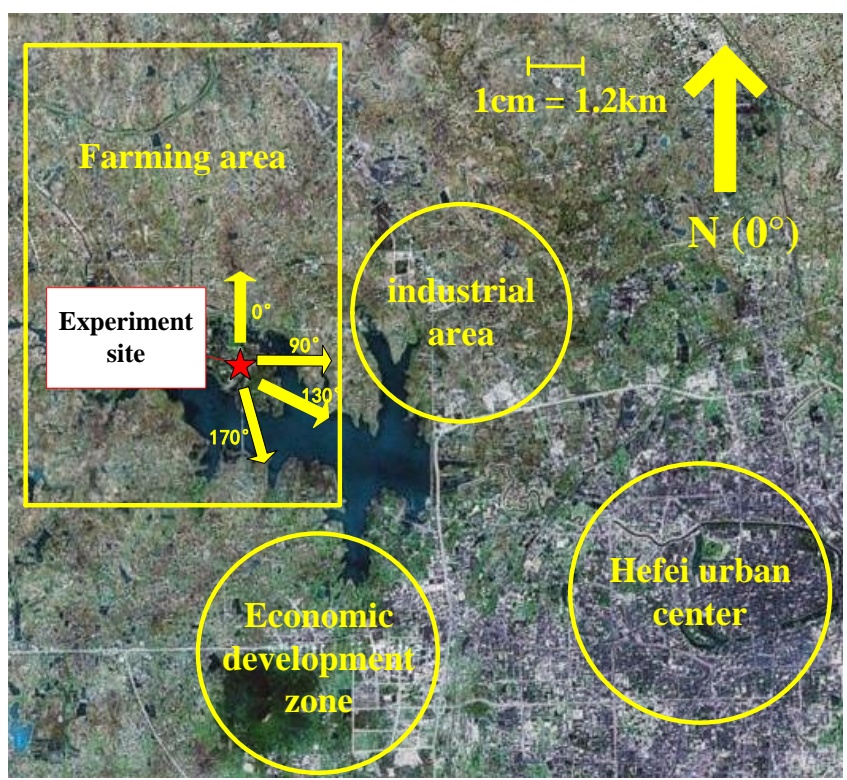

Figure 10. The experiment site was located approximately $6 \mathrm{~km}$ away from the downtown in the north-west outskirts of Hefei. The four azimuth angles point to a farming area, an industrial area, an urban centre, and an economic development zone. The GM-DOAS and LP-DOAS instruments were located at the experiment site. The distance between the two instruments was less than $100 \mathrm{~m}$.

current. The spectral resolution of the instrument (full width at half maximum) is $0.35 \mathrm{~nm}$.

The experiment site is approximately $6 \mathrm{~km}$ away from the urban centre and located in the north-west outskirts of Hefei (Fig. 10). The telescope is sequentially pointed to four azimuth angles $\left(0^{\circ}, 90^{\circ}, 130^{\circ}\right.$, and $\left.170^{\circ}\right)$. These angles correspond to the following areas: farming region, industrial area, downtown, and economic development zone. For each azimuth angle, the spectra are measured at elevation angles of $1^{\circ}$ and $90^{\circ}$. The experiment was performed from 08:00 to 16:00 local time on mostly sunny days $(16,18$, and 21 May as well as 3 June 2012); the corresponding SZAs are always $<60^{\circ}$.

\subsection{The LP-DOAS instrument}

A LP-DOAS instrument was operated at a distance of less than $100 \mathrm{~m}$ from the GM-DOAS instrument. From the LPDOAS observations trace gas VMR of $\mathrm{NO}_{2}, \mathrm{HCHO}$, and $\mathrm{SO}_{2}$ are determined, which are well suited for comparison with the GM-DOAS observations. The LP-DOAS instrument consists of an artificial light source (xenon arc lamp) and a coaxial Newtonian telescope with combined transmitting and receiving optic fibers. A retro reflector array (located $350 \mathrm{~m}$ away and approximately $30 \mathrm{~m}$ above the ground) is used for reflecting the light exactly back into the telescope, where it is focused onto a quartz fiber. The quartz fiber transmits the light into a spectrograph. Given that the total light 


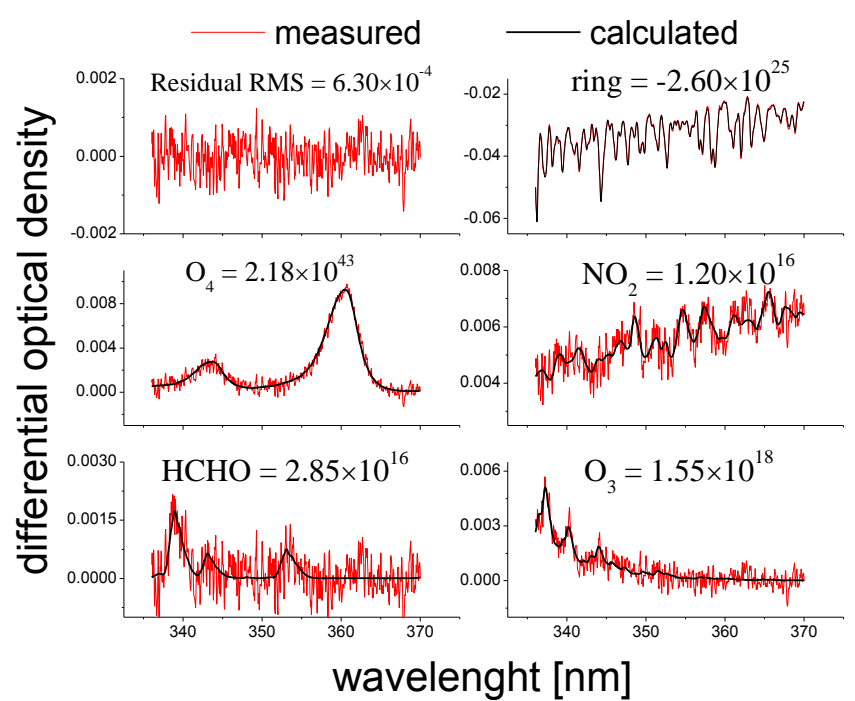

Figure 11. Example of a DOAS fit of $\mathrm{O}_{4}$ and $\mathrm{NO}_{2}$ at 12:45 (local time) on 16 May 2012. The Fraunhofer reference spectrum used was the latest $90^{\circ}$ spectrum before the measurement. The results were as follows: $\operatorname{dAMF}\left(\mathrm{O}_{4}\right)=(1.83 \pm 0.12)$ and $\operatorname{dSCD}\left(\mathrm{NO}_{2}\right)=(1.2 \pm$ $0.08) \times 10^{16}$ molecules $\mathrm{cm}^{-2}$. The RMS of the residual was $6.3 \times$ $10^{-4}$.

path is approximately $700 \mathrm{~m}$, the integrated column density along the light path can be easily and exactly transformed into VMR.

\section{Data analysis, comparison with LP-DOAS, and discussion}

\subsection{Spectral retrieval of $\mathrm{O}_{4}, \mathrm{NO}_{2}, \mathrm{SO}_{2}$, and $\mathrm{HCHO}$}

Based on the Lambert-Beer law, different trace gases can be retrieved using the DOAS algorithm in different spectral ranges. We used the WINDOAS software (Fayt and van Roozendael, 2009) to analyse the measured spectra. The fitted polynomial degree was 3 . The effect of Raman scattering was compensated by fitting a synthetic ring spectrum (Grainger and Ring, 1962; Solomon et al., 1987; Wagner et al., 2009) as an additional pseudo-absorber. This ring spectrum was computed using the DOAS Intelligent System (DOASIS) software (Kraus, 2006). The absorption cross sections of $\mathrm{O}_{4}$ at $296 \mathrm{~K}$ (Greenblatt et al., 1990), $\mathrm{NO}_{2}$ at $294 \mathrm{~K}$ (Vandaele et al., 1998), HCHO at $298 \mathrm{~K}$ (Meller and Moortgat, 2000), $\mathrm{O}_{3}$ at $223 \mathrm{~K}$ (Bogumil et al., 2003) and $\mathrm{SO}_{2}$ at 293 K (Bogumil et al., 2003) are used in the DOAS fits. For each azimuth angle, the spectra at the elevation angle of $1^{\circ}$ and $90^{\circ}$ were successively acquired. The spectrum at the elevation angle of $1^{\circ}$ was fitted with the spectrum in the zenith view as the Fraunhofer reference spectrum. For $\mathrm{NO}_{2}$ and $\mathrm{O}_{4}$, the spectra were analysed in the wavelength range of $336 \mathrm{~nm}$ to $370 \mathrm{~nm}$. The window contains two $\mathrm{O}_{4}$ absorption bands at

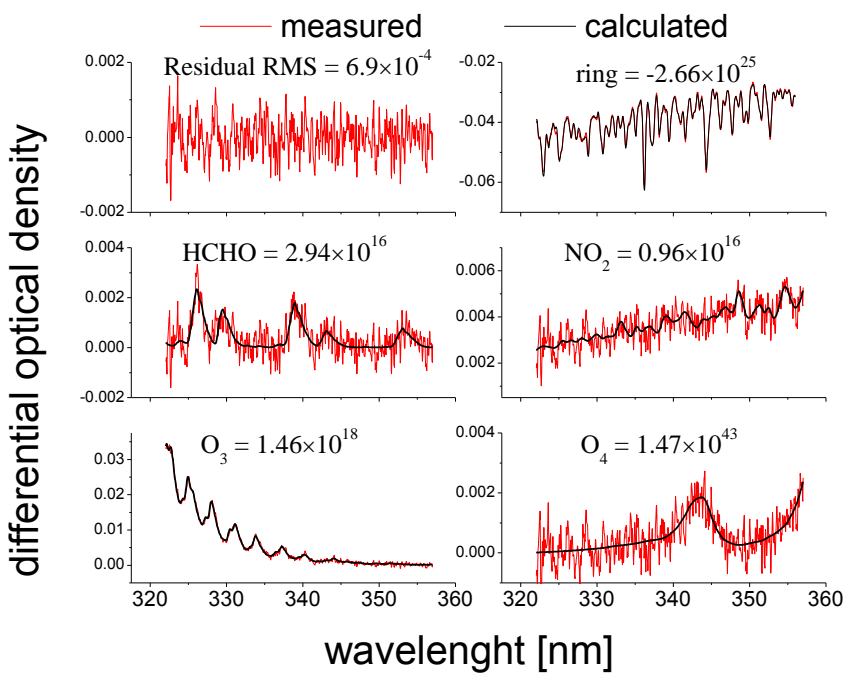

Figure 12. Example of a DOAS fit of $\mathrm{HCHO}$ at 12:45 (local time) on 16 May 2012. The Fraunhofer reference spectrum used was the latest $90^{\circ}$ spectrum before the measurement. The derived $\mathrm{HCHO}$ $\mathrm{dSCD}$ was $(2.94 \pm 0.16) \times 10^{16}$ molecules $\mathrm{cm}^{-2}$. The RMS of the residual was $6.9 \times 10^{-4}$.

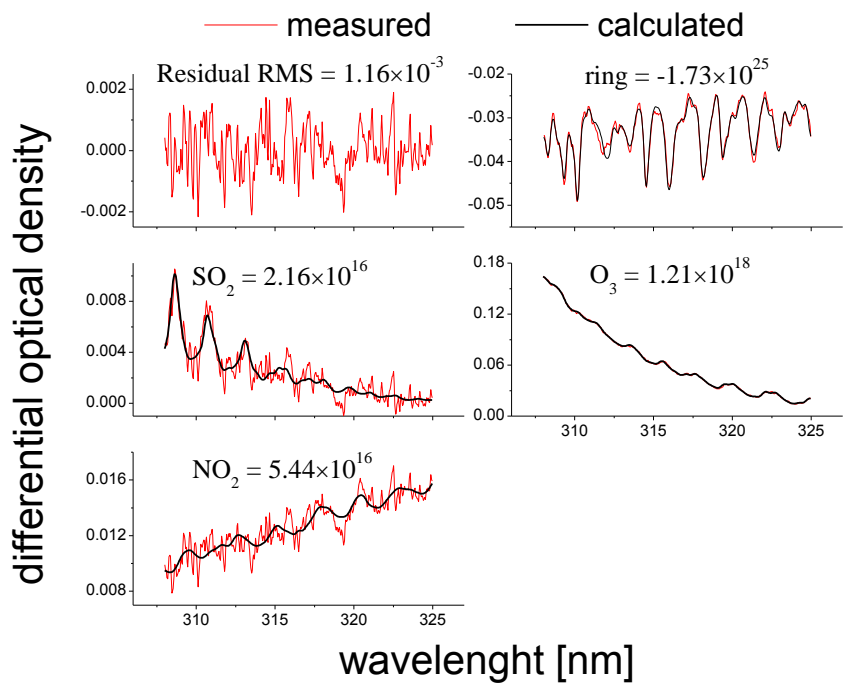

Figure 13. Example of a DOAS fit of $\mathrm{SO}_{2}$ at 12:45 (local time) on 16 May 2012. The Fraunhofer reference spectrum used was the latest $90^{\circ}$ spectrum before the measurement. The derived $\mathrm{SO}_{2} \mathrm{dSCD}$ was $(2.16 \pm 0.22) \times 10^{16}$ molecules $\mathrm{cm}^{-2}$. The RMS of the residual was $1.16 \times 10^{-3}$

343 and $360 \mathrm{~nm}$. Here, it should be noted that the derived $\mathrm{O}_{4}$ dAMF is dominated by the much stronger $\mathrm{O}_{4}$ absorption at $360 \mathrm{~nm}$. Besides the cross sections of $\mathrm{O}_{4}$ and $\mathrm{NO}_{2}$, the cross sections of $\mathrm{O}_{3}$ and $\mathrm{HCHO}$ were also considered. An example of the spectral fit from 16 May 2012 at 12:45 (local time) is shown in Fig. 11. 


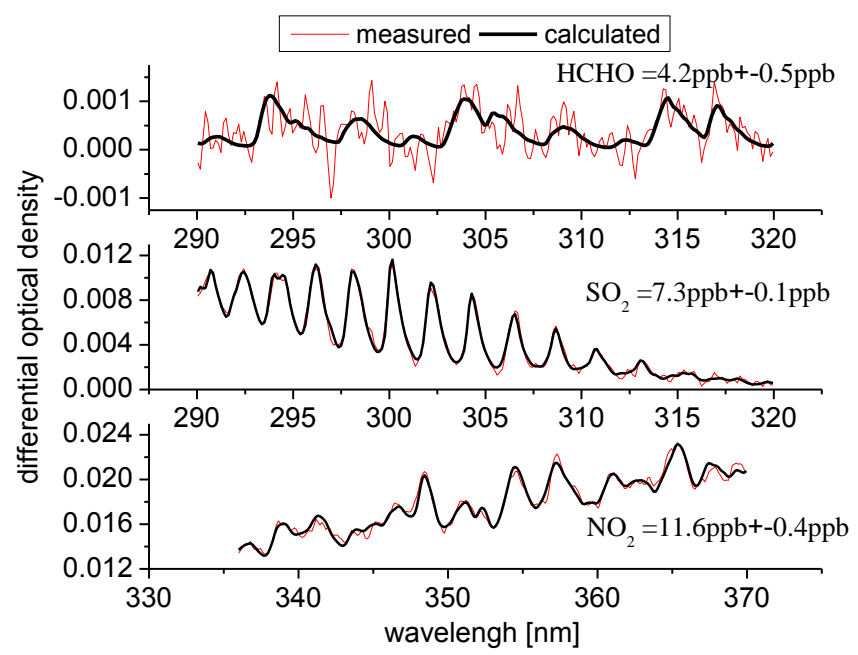

Figure 14. Example of LP-DOAS fits of $\mathrm{HCHO}, \mathrm{SO}_{2}$, and $\mathrm{NO}_{2}$ at 09:05 (local time) on 18 May 2012. The results are as follows: $\operatorname{VMR}(\mathrm{HCHO})=4.2 \pm 0.5 \mathrm{ppb}, \mathrm{VMR}\left(\mathrm{SO}_{2}\right)=7.3 \pm 0.1 \mathrm{ppb}$, and $\operatorname{VMR}\left(\mathrm{NO}_{2}\right)=11.6 \pm 0.4 \mathrm{ppb}$.

Figures 12 and 13 show typical examples of $\mathrm{HCHO}$ and $\mathrm{SO}_{2}$ fits in the spectral ranges of $322 \mathrm{~nm}$ to $356 \mathrm{~nm}$, and $308 \mathrm{~nm}$ to $325 \mathrm{~nm}$, respectively. The determined trace gas dSCDs for the selected examples are as follows: the $\mathrm{NO}_{2}$ dSCD was $(1.2 \pm 0.08) \times 10^{16}$ molecules $\mathrm{cm}^{-2}$, the HCHO dSCD was $(2.94 \pm 0.16) \times 10^{16}$ molecules $\mathrm{cm}^{-2}$, and the $\mathrm{SO}_{2}$ $\mathrm{dSCD}$ was $(2.16 \pm 0.22) \times 10^{16}$ molecules $\mathrm{cm}^{-2}$. The effective light path lengths derived from the $\mathrm{O}_{4} \mathrm{dAMF}$ (and according to Eqs. 6 and 7) are $7.8 \pm 0.51 \mathrm{~km}, 7.1 \pm 0.47 \mathrm{~km}$, and $5.7 \pm 0.37 \mathrm{~km}$ for $360 \mathrm{~nm}, 340 \mathrm{~nm}$, and $310 \mathrm{~nm}$, respectively. Using these results, the following trace gas VMR were derived: for $\mathrm{NO}_{2}: 0.6 \pm 0.04 \mathrm{ppb}$, for $\mathrm{HCHO}: 1.7 \pm 0.1 \mathrm{ppb}$, and for $\mathrm{SO}_{2}: 1.5 \pm 0.12 \mathrm{ppb}$.

The DOAS fit examples for LP-DOAS are shown in Fig. 14. All absorption cross sections for LP-DOAS (except $\mathrm{O}_{3}$ at $293 \mathrm{~K}$ from Bogumil et al., 2003) are the same as for the rapid MAX-DOAS method (GM-DOAS). For $\mathrm{NO}_{2}$ the same fitting window as for the GM-DOAS was used. For $\mathrm{SO}_{2}$ and $\mathrm{HCHO}$, a different fitting window (from $290 \mathrm{~nm}$ to $320 \mathrm{~nm}$ ) was used, which is more suitable according to the specific properties of the LP-DOAS instrument.

\subsection{Differential light path lengths and correction factors}

The differential light path lengths near the ground at $360 \mathrm{~nm}$ were calculated based on the $\mathrm{O}_{4}$ dSCDs retrieved during the four days using Eq. (1). Figure 15 shows these differential light path lengths and the corresponding probed altitude ranges that were geometrically calculated using Eq. (8). The diurnal variation of the light path lengths (usually smaller $L$ in the morning and evening) is probably a consequence of the varying aerosol extinction close to the surface. The results indicate that the horizontal distance, which MAX-DOAS

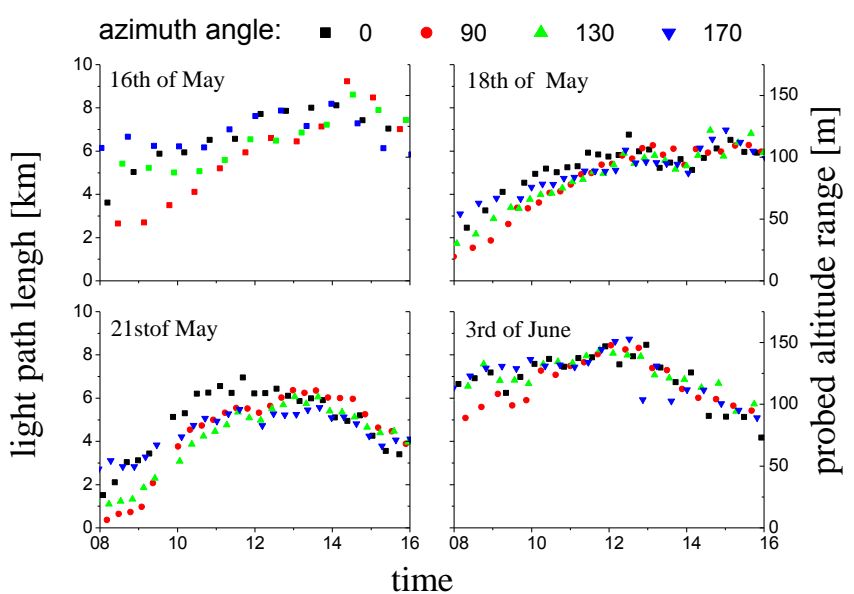

Figure 15. Effective light path lengths and probed altitude ranges at $360 \mathrm{~nm}$ near the ground for observations at $1^{\circ}$ elevation angle during four selected days. The black, red, green, and blue dots correspond to $0^{\circ}$ (north), $90^{\circ}$ (east), $130^{\circ}$ (south-east), and $170^{\circ}$ (south).

observations at $1^{\circ}$ elevation angle are sensitive for, can reach approximately $6 \mathrm{~km}$ to $9 \mathrm{~km}$ at noon, which corresponds to probed altitude ranges up to approximately $100 \mathrm{~m}$ to $160 \mathrm{~m}$. Using Eqs. (6, 7, and 8), slightly lower effective light path lengths and probed altitude ranges were derived for $340 \mathrm{~nm}$ and $310 \mathrm{~nm}$ (not shown). Interestingly, the results for the different azimuth angles are very similar and show the same diurnal variations. However, the effective light path lengths from the north-facing view are typically slightly larger than those of the other directions. This result indicates smaller aerosol extinction from the north-facing view.

The time series of the average correction factors and their corresponding uncertainties (for $\mathrm{NO}_{2}, \mathrm{HCHO}$, and $\mathrm{SO}_{2}$ ) for four azimuth angles during the period of the experiment determined from the measured $\mathrm{O}_{4}$ dAMF are shown in Fig. 16. Especially in the morning (and for high aerosol load), the uncertainties of the correction factors for the viewing direction with azimuth angle of $90^{\circ}$ can become rather large. This is caused by the small RAA for these measurements (see Sect. 2.3).

\subsection{Results and comparisons}

Before we report and discuss the average $\mathrm{NO}_{2}, \mathrm{SO}_{2}$, and HCHO VMRs in the boundary layer derived from four azimuth angles using the rapid MAX-DOAS method, we give a brief overview on some meteorological parameters on the four selected days. Wind directions and speeds are shown in Fig. 17. The main wind direction during the four days was south-east except on 16 May when it was south-west (Fig. 17a). The time series of the hourly average wind speed (Fig. 17b) indicates that air mass transport was more effective during daytime. 


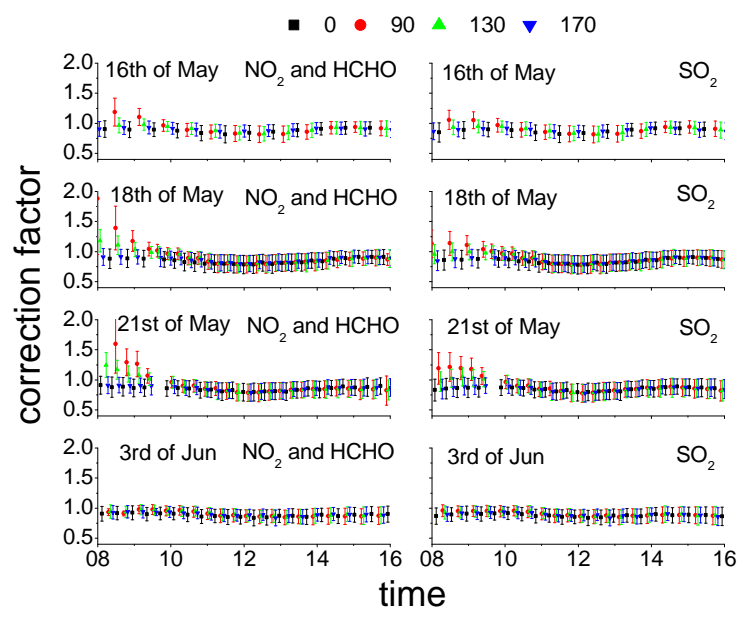

Figure 16. Time series of the average correction factors and their corresponding uncertainties for $\mathrm{NO}_{2}, \mathrm{HCHO}$, and $\mathrm{SO}_{2}$ for four azimuth angles during the period of the experiment.
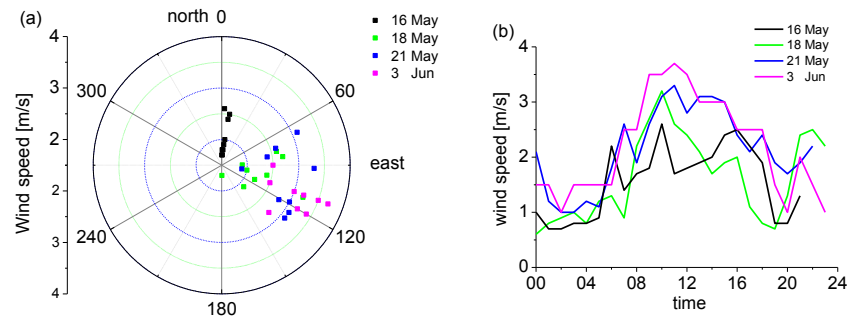

Figure 17. Wind direction and speed on 16, 18, and 21 May and 3 June 2012. (a) Wind rose plot and (b) time series of hourly average wind speed.

Figures 18, 19, and 20 show the time series of average $\mathrm{NO}_{2}, \mathrm{SO}_{2}$, and $\mathrm{HCHO} \mathrm{VMRs}$ for $0^{\circ}, 90^{\circ}, 130^{\circ}$, and $170^{\circ}$ azimuth angles, respectively, as well as the corresponding VMR derived from LP-DOAS for comparison. Note that data points with RAA $<50^{\circ}$ were excluded, because for such measurements the uncertainties are especially large (see Sect. 2.3). The corresponding figure with all data points included is shown in the Supplement. Figure 21a, b, and c present the daily mean values of the three trace gases for the different directions. For the four azimuth angles, similar daily evolutions of the trace gas VMR are found confirming that no strong horizontal inhomogeneities were present in the surrounding area (according to an effective light path length of $6 \mathrm{~km}$, this area is approximately $130 \mathrm{~km}^{2}$ ). Compared to $\mathrm{NO}_{2}$ and $\mathrm{SO}_{2}$, for $\mathrm{HCHO}$ the temporal variability and the differences between the different azimuth angles are much smaller. This indicates that the horizontal gradients are in general smoother for HCHO. Interestingly, on 21 May, larger differences are found for all trace gases indicating significant gradients of the VMR around the measurement site. Stronger gradients on that day are also indicated by the rapid

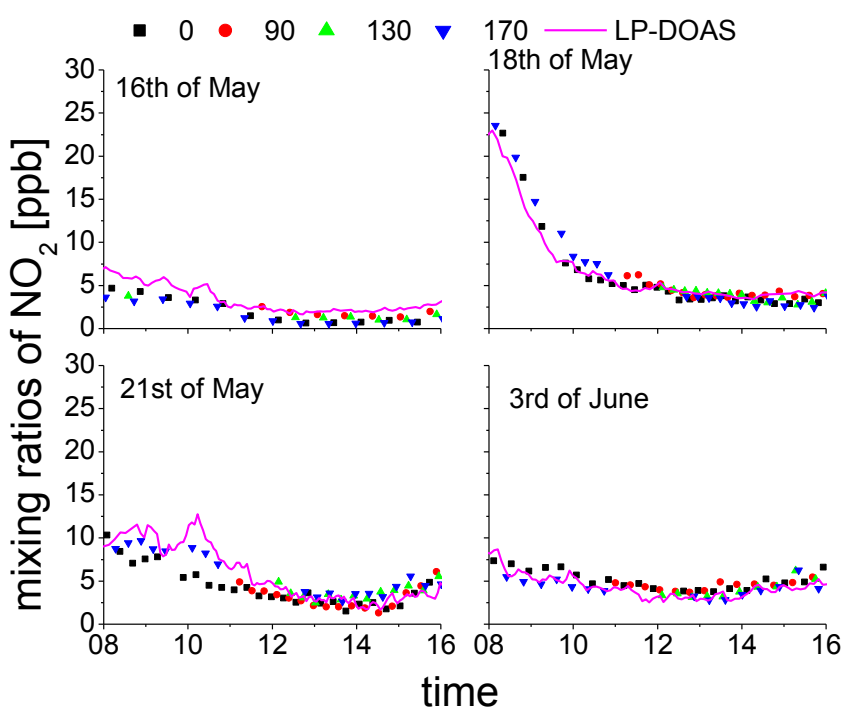

Figure 18. Time series of the average $\mathrm{NO}_{2} \mathrm{VMR}$ near the ground from the rapid MAX-DOAS method compared with that from LPDOAS. The legend explaining the dots is the same as that indicated in Fig. 15. The magenta lines indicate the curves of $\mathrm{NO}_{2} \mathrm{VMR}$ from LP-DOAS.

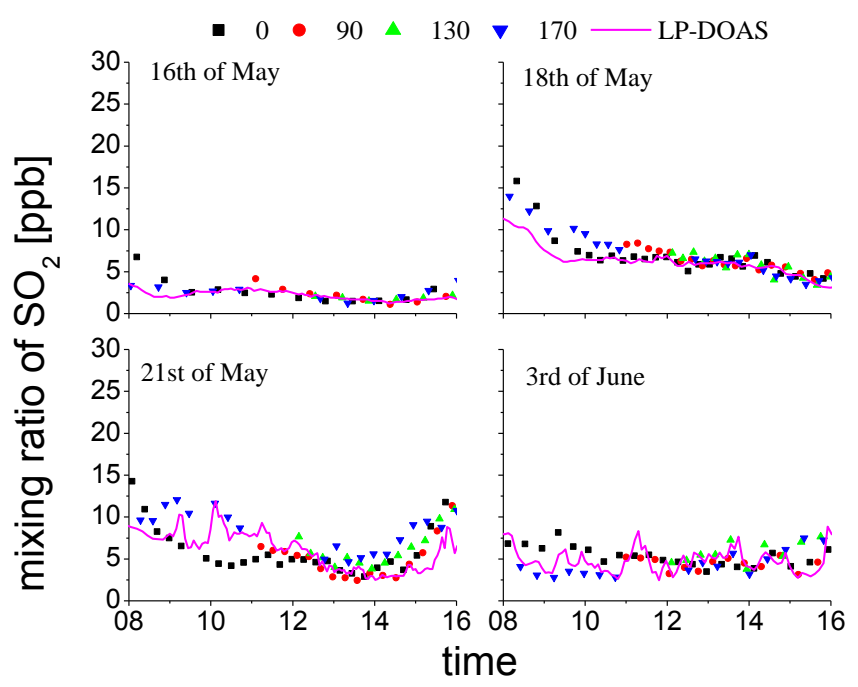

Figure 19. Time series of average $\mathrm{SO}_{2} \mathrm{VMR}$ near the ground from the rapid MAX-DOAS method compared with that from LP-DOAS.

temporal variations of the $\mathrm{VMR}$ of $\mathrm{NO}_{2}$ and $\mathrm{SO}_{2}$ retrieved from LP-DOAS. Here it should be noted that the LP-DOAS monitors the average VMR over a rather short distance of $350 \mathrm{~m}$. By comparison, the rapid MAX-DOAS method measures large-scale $(2 \mathrm{~km}$ to $9 \mathrm{~km})$ average VMRs. Therefore, the temporal variations of the rapid MAX-DOAS method are much smoother than those of the LP-DOAS measurements.

To verify the reliability of the rapid MAX-DOAS method, the linear regressions and statistical parameters of the average hourly VMRs from LP-DOAS and MAX-DOAS for the 


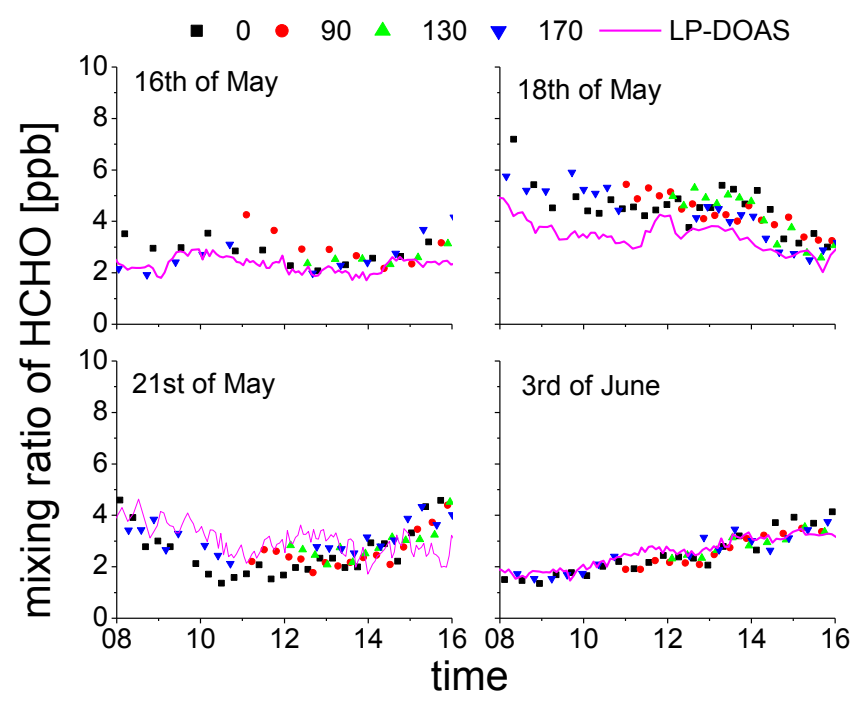

Figure 20. Time series of average HCHO VMR near the ground from the rapid MAX-DOAS method compared with that from LPDOAS.

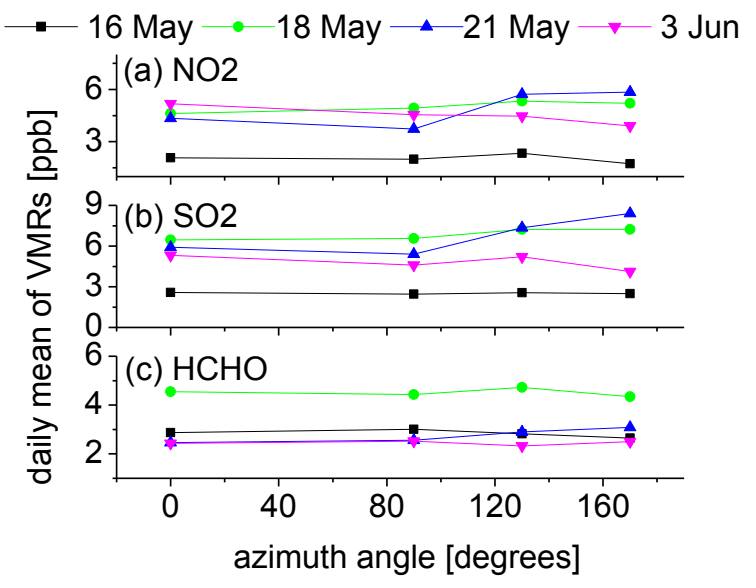

Figure 21. Comparisons of the daily mean $\mathrm{NO}_{2}$ (a), $\mathrm{HCHO}$ (b), and $\mathrm{SO}_{2}$ (c) VMRs near the ground for different azimuth angles.

three trace gases were calculated (Fig. 22). The azimuth angles of the measurement were not distinguished in the statistical process. The squares of the correlation coefficients for $\mathrm{NO}_{2}, \mathrm{SO}_{2}$, and $\mathrm{HCHO}$ were $0.92,0.85$, and 0.60 , respectively. The weaker correlation for $\mathrm{HCHO}$ and $\mathrm{SO}_{2}$ are mainly caused by the larger uncertainties of the DOAS fit and the transformation of the light path length from $360 \mathrm{~nm}$ to $340 \mathrm{~nm}$ and $310 \mathrm{~nm}$, respectively. The slopes of the regression lines for $\mathrm{NO}_{2}, \mathrm{SO}_{2}$, and $\mathrm{HCHO}$ are $0.85,0.72$, and 0.45 , respectively. Slopes smaller than 1 indicate that the VMRs from LP-DOAS are generally smaller than those from MAXDOAS. The positive intercepts indicate that the VMRs from LP-DOAS are generally larger than those from MAX-DOAS when the concentrations of the trace gases are relatively low. The reason for this difference is currently not clear, but may
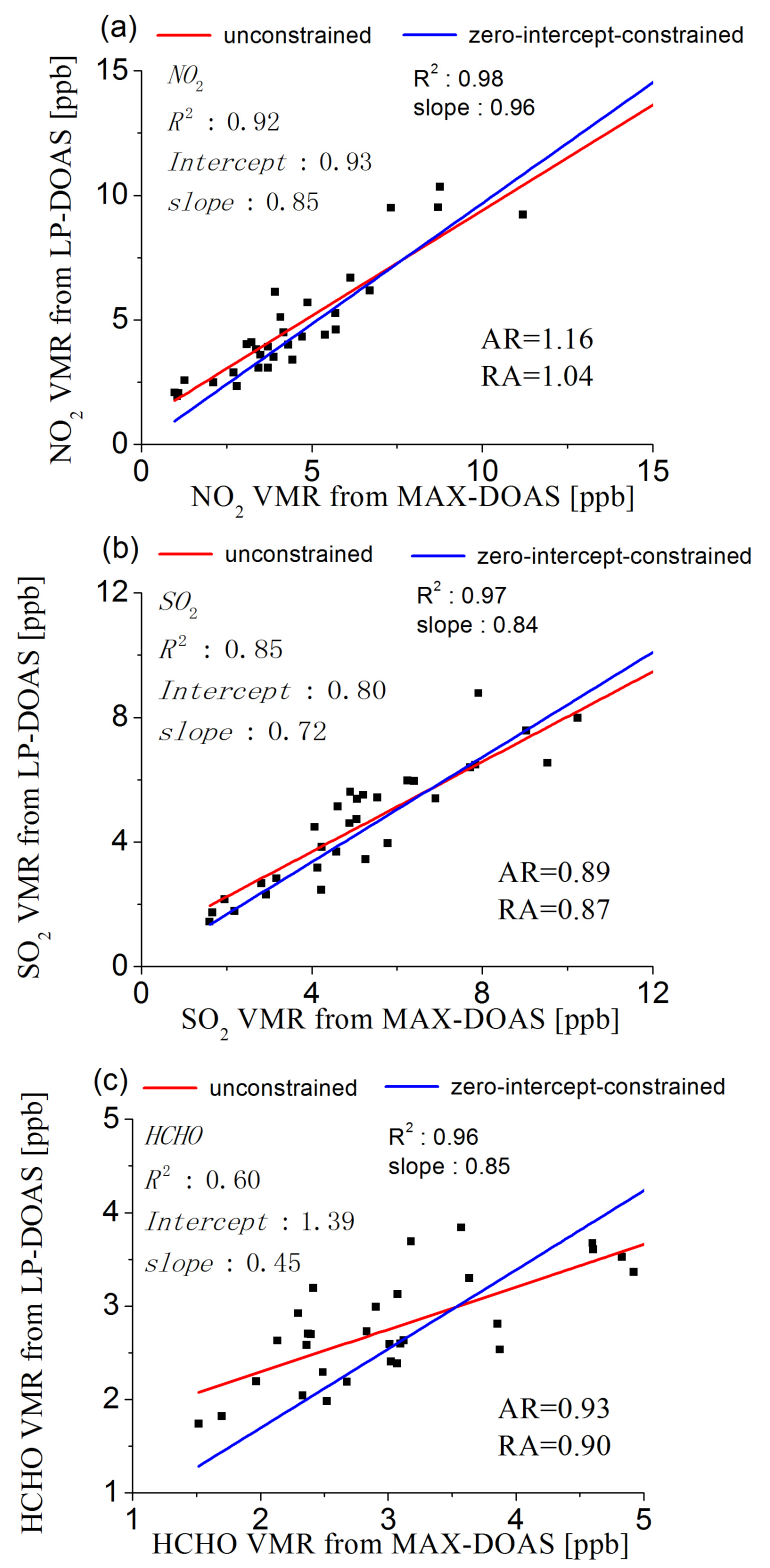

Figure 22. Scatter plots and linear regression curves for the hourly average $\mathrm{NO}_{2}$ (a), $\mathrm{SO}_{2}$ (b), and $\mathrm{HCHO}$ (c) VMRs from LP-DOAS against that from MAX-DOAS. The red lines indicate the unconstrained linear fit and blue ones indicate the zero-intercept constrained linear fit.

be caused by the different altitude ranges and horizontal distances, for which both methods are sensitive. The VMR from the rapid MAX-DOAS method represents the average for the probed altitude range (typically $<200 \mathrm{~m}$ ), while the LP-DOAS observations are representative for the trace gas VMR close to the surface. The rapid method usually integrates over horizontal distances of several kilometres, while the LP-DOAS observations are representative for a light path of only $350 \mathrm{~m}$. 
In addition to the slopes and intercepts of the regression lines, we also calculated the average of the ratios (AR) and the ratio of averages (RA) of all data pairs from MAX-DOAS and LP-DOAS data for each trace gas using Eqs. (10) and (11), respectively. Here it should be noted that RA is similar to the slope of the regression lines if they are forced to the origin. The $\mathrm{NO}_{2} \mathrm{AR}$ and RA are 1.16 and 1.04, respectively. For $\mathrm{SO}_{2}$, the AR and RA are 0.89 and 0.87 , respectively. For $\mathrm{HCHO}$, the AR and RA are 0.93 and 0.90, respectively. Like for the slopes of the regression lines, these ratios are also higher for $\mathrm{NO}_{2}$ than for the other two trace gases. These findings probably indicate that the $\mathrm{NO}_{2}$ profile probably has a steeper vertical gradient close to the surface than $\mathrm{SO}_{2}$ and HCHO. For measurements close to strong emission sources, such differences in the vertical profiles might be expected due to the different atmospheric lifetimes (usually with the shortest lifetime for $\mathrm{NO}_{2}$ ).

$$
\begin{aligned}
\mathrm{AR} & =\frac{1}{n} \sum_{i=1}^{n} \frac{\mathrm{VMR}_{\mathrm{LP}^{-D O A S}}}{\mathrm{VMR}_{\mathrm{MAX}-\mathrm{DOAS}_{i}}} \\
\mathrm{RA} & =\frac{\frac{1}{n} \sum_{i=1}^{n} \mathrm{VMR}_{\mathrm{LP} \mathrm{DOAS}_{i}}}{\frac{1}{n} \sum_{i=1}^{n} \mathrm{VMR}_{\mathrm{MAX}-\mathrm{DOAS}_{i}}}
\end{aligned}
$$

In Eqs. (10) and (11), $n$ indicates the number of hourly average VMR for each trace gas.

To study further the horizontal distribution of the observed trace gases, the statistical parameters of the linear regression curves of hourly average VMRs for each trace gas were determined for the four azimuth angles separately (Table 2). The ARs and RAs for the four azimuth angles are also shown in the Table 2 .

\section{Retrieval of the surface aerosol extinction from the measured $\mathrm{O}_{4} \mathrm{dAMF}$}

Radiative transfer simulations show a clear relationship between the near-surface aerosol extinction and the $\mathrm{O}_{4} \mathrm{dAMF}$ for the $1^{\circ}$ elevation angle (Fig. 23). This relationship depends on SZA (and also slightly on RAA). As expected, the vertical extension of the aerosol layer causes a relatively small uncertainty in this relationship, because the observations at $1^{\circ}$ elevation angle are mainly sensitive for the atmospheric layers close to the surface. Thus, the aerosol extinction at the surface can be well retrieved from the measured $\mathrm{O}_{4} \mathrm{dAMF}$ using the rapid MAX-DOAS method. In Fig. 24 the aerosol extinction derived from the MAX-DOAS observations at $1^{\circ}$ elevation angle are shown for the four days of the experiment. On 16 May and 3 June, rather low aerosol extinctions are found; on the two other days, the values are systematically higher. In general very good agreement between the results of the rapid method and the results from forward-scattering visibility meters (Manufacturer: Anhui Landun Photoelectron Co.,
Table 2. Statistical parameters of the correlation between LP-DOAS and MAX-DOAS for four azimuth angles and each trace gas.

\begin{tabular}{llcccc}
\hline $\begin{array}{l}\text { Azimuth angle } \\
\text { GAS }\end{array}$ & Statistical & $0^{\circ}$ & $90^{\circ}$ & $130^{\circ}$ & $170^{\circ}$ \\
& Parameters & & & & \\
\hline & $R^{2}$ & 0.84 & 0.59 & 0.87 & 0.90 \\
$\mathrm{NO}_{2}$ & Intercept (ppb) & 1.20 & 0.82 & 1.04 & 1.34 \\
& slope & 0.86 & 0.78 & 0.75 & 0.78 \\
& AR & 1.35 & 1.06 & 1.09 & 1.35 \\
& RA & 1.12 & 0.99 & 0.98 & 1.06 \\
\hline \multirow{5}{*}{$\mathrm{SO}_{2}$} & $R^{2}$ & 0.74 & 0.70 & 0.79 & 0.73 \\
& Intercept (ppb) & 1.23 & 0.91 & 0.98 & 1.50 \\
& slope & 0.64 & 0.73 & 0.64 & 0.58 \\
& AR & 0.93 & 0.97 & 0.85 & 0.94 \\
& RA & 0.88 & 0.93 & 0.81 & 0.85 \\
\hline $\mathrm{HCHO}^{2}$ & $R^{2}$ & 0.46 & 0.23 & 0.52 & 0.62 \\
& Intercept (ppb) & 1.67 & 2.00 & 1.54 & 1.27 \\
& slope & 0.37 & 0.25 & 0.39 & 0.50 \\
& AR & 0.99 & 0.95 & 0.94 & 0.93 \\
& RA & 0.91 & 0.89 & 0.88 & 0.90 \\
\hline
\end{tabular}

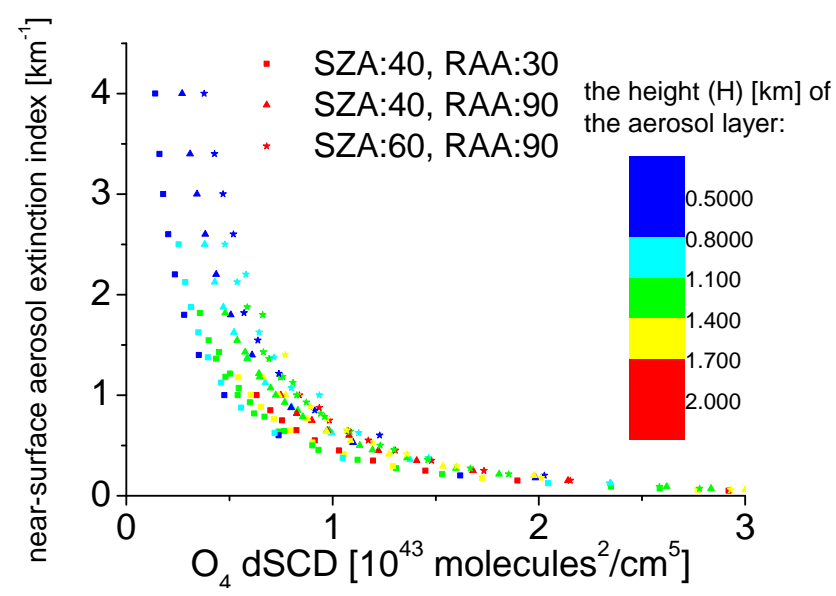

Figure 23. Near-surface aerosol extinction as function of the $\mathrm{O}_{4}$ dAMF measured at $1^{\circ}$ elevation for three selected viewing geometries: Rectangles, triangles, and stars indicate simulation results for SZA $40^{\circ}$ and RAA $30^{\circ}$, SZA $40^{\circ}$ and RAA $90^{\circ}$, and SZA $60^{\circ}$ and RAA $90^{\circ}$, respectively. The colours of the symbols indicate the height of the aerosol layer (in $\mathrm{km}$ ).

Ltd. Model: DNQ2 forward-scattering visibility meters) is also found. Here, however, it should be noted that no exact agreement can be expected because both measurements are based on different techniques and use different assumptions: the aerosol extinctions from the visibility meters are derived from forward-scattered signal of a light-emitting diode at $950 \mathrm{~nm}$. The results are converted to $550 \mathrm{~nm}$ using an empirical conversion formula (Nebuloni, 2005). It should also be noted that the detection limit of the visibility meters is about $0.15 \mathrm{~km}^{-1}$. So after 11:00 on 16 May the true value of the aerosol extinction is probably lower than $0.15 \mathrm{~km}^{-1}$. 


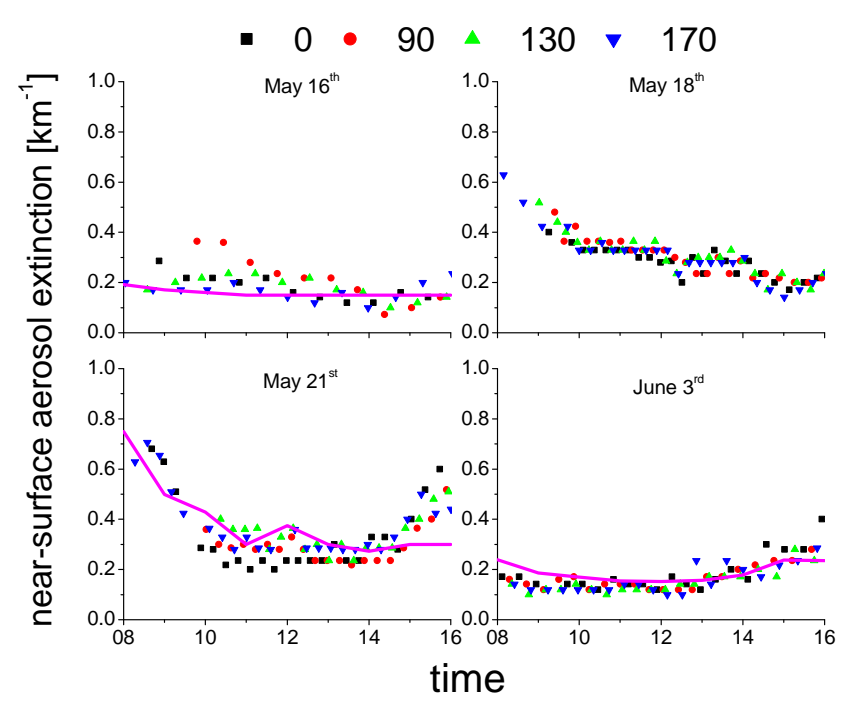

Figure 24. Aerosol extinction close to the surface derived from the measured $\mathrm{O}_{4} \mathrm{dAMF}$ for four viewing azimuth angles of $0^{\circ}$ (black), $90^{\circ}$ (red), $130^{\circ}$ (green), and $170^{\circ}$ (blue), respectively. The magenta lines indicate the results from visibility meter measurements at the top of the institute (16 May and 3 June) and Hefei airport (21 May) (the distance between the experiment location and the airport site is about $20 \mathrm{~km}$ ).

Overall, the derived aerosol extinction values show similar spatial and temporal variation as the $\mathrm{NO}_{2}$ and $\mathrm{SO}_{2} \mathrm{VMR}$, indicating a common emission source.

\section{Error discussion}

According to Eqs. (1), (2), and (3), several factors contribute to the overall error of the trace gas concentrations. Since we can assume that these errors are mostly independent, the total relative error of the trace gas concentrations (or mixing ratios) is given by the following formula:

$$
\begin{aligned}
& \frac{\Delta c_{\text {tracegas }}}{c_{\text {tracegas }}}= \\
& \sqrt{\left(\frac{\Delta \mathrm{dSCD}_{\text {tracegas }}}{\mathrm{dSCD}}\right) \cdot\left(\frac{\Delta \mathrm{dAMF}_{\text {tracegas }}}{\mathrm{dAMF}_{4}}\right) \cdot\left(\frac{\Delta f_{\text {corr }}}{f_{\text {corr }}}\right)} .
\end{aligned}
$$

The errors of the trace gas dSCDs are determined by the uncertainty of the DOAS fit. The residual of the DOAS fit mainly contains noise and only some weak systematic structures. For $\mathrm{O}_{4}$ and $\mathrm{NO}_{2}$, the typical RMS was $6 \times$ $10^{-4}$, which corresponds to $\mathrm{NO}_{2}$ and $\mathrm{O}_{4}$ fitting errors of $8 \times 10^{14}$ molecules $\mathrm{cm}^{-2}$ and $1.4 \times 10^{42}$ molecules $^{2} \mathrm{~cm}^{-5}$, respectively (the corresponding uncertainty of the $\mathrm{O}_{4} \mathrm{dAMF}$ is 0.12). The typical RMS of the residual for the HCHO fit was $7 \times 10^{-4}$, corresponding to an error of the HCHO dSCD of $1.6 \times 10^{15}$ molecules $\mathrm{cm}^{-2}$. The fitting window of $\mathrm{SO}_{2}$ was close to the solar-blind region. Thus, the signal to noise ratio of the spectra was relatively low. In this case, the typical
RMS of the residual was $1.2 \times 10^{-3}$, which corresponds to an error of the $\mathrm{SO}_{2} \mathrm{dSCD}$ of $2.2 \times 10^{15}$ molecules $\mathrm{cm}^{-2}$. The uncertainty of the absorption cross-sections of the trace gases, which depends on atmospheric temperature and pressure, may contribute to an additional $10 \%$ relative error. This systematic error is usually smaller than the other error sources and is neglected here.

The uncertainty of $f_{\text {corr }}$ is estimated from the spread of correction factors calculated for a large variety of assumed trace gas and aerosol profiles (see Sect. 2.3). The typical uncertainty is about $14 \%$. For high atmospheric visibility $\left(\mathrm{O}_{4}\right.$ $\mathrm{dAMF}>$ about 2) the uncertainties are usually smaller and for low atmospheric visibility $\left(\mathrm{O}_{4} \mathrm{dAMF}<\right.$ about 1$)$ and specific observation geometries (see Fig. 7) the uncertainties can become substantially larger. Here it should again be noted that the uncertainties of $f_{\text {corr }}$ should be seen as a lower limit because for individual cases the trace gas profiles might be different from the assumed profiles.

For our measurements, according to Eq. (12), the total uncertainty of the retrieved trace gas VMR is typically between $20 \%$ and $30 \%$.

For the retrieval of the surface extinction, the error is caused by the uncertainty of the DOAS fit for $\mathrm{O}_{4}$ (see above) and by the missing knowledge of the shape of the aerosol extinction profile. The latter uncertainty can be directly derived from the results shown in Fig. 23. For aerosol extinctions $<0.5$ the total error is usually dominated by the uncertainties of the DOAS fit for $\mathrm{O}_{4}$ (about $15 \%$ ). For aerosol extinctions $>0.5$ the uncertainties caused by the missing knowledge of the aerosol extinction profile dominates the total uncertainty. For aerosol extinctions $<1$ the total error is about $50 \%$ and increases rapidly for higher values.

It should be noted that for specific observation geometries $\left(\mathrm{SZA}>70^{\circ}, \mathrm{RAA}<50^{\circ}\right)$ the uncertainties of the correction factors becomes especially large. Thus we recommend that the rapid method should be applied for $\mathrm{SZA}<70^{\circ}$ and $\mathrm{RAA}>50^{\circ}$ to ensure that the uncertainties are mainly $<20 \%$. In this study, the SZA was always $<60^{\circ}$, but we excluded measurements with RAA $<50^{\circ}$.

It should also be noted that the uncertainties can become much larger in cases of very strong horizontal and/or vertical gradients, e.g. in close vicinity of very strong emission sources. In such cases, the proposed method should be used with caution. However, it should also be noted that in such situations the uncertainties of other methods (e.g. LP-DOAS) are also usually large. Furthermore, in the presence of strong spatial gradients also the representativeness of in situ measurements is limited.

In addition to the observations at $1^{\circ}$ elevation angle, future measurements might also add observation at a higher elevation angle (e.g. $2^{\circ}$ ) in order to derive information about the presence of very strong vertical gradients close to the surface (such as the "collapsing criterium" used in Sinreich et al., 2013). Here it is important to note that these measurements at higher elevation angles could be performed with a coarser 
temporal resolution compared to the main observations at $1^{\circ}$ elevation.

\section{Conclusions}

We performed rapid measurements of near-surface trace gas VMRs and aerosol extinction using MAX-DOAS measurements at $1^{\circ}$ elevation angle. This method (for trace gases) was recently introduced by Sinreich et al. (2013), but we apply several important modifications: We restrict the measurements to $1^{\circ}$ elevation angles, for which the uncertainty due to influence of the relative profile shape of the trace gases or aerosols on the retrieved results is usually much smaller than for higher elevation angles. The restriction to only $1^{\circ}$ elevation angle also leads to a higher temporal and spatial resolution. We parameterize the correction factors (and their uncertainties) as function of the corresponding $\mathrm{O}_{4} \mathrm{dAMF}$. In this way the correction factors can be directly determined according to the retrieved $\mathrm{O}_{4}$ dAMF of a given measurement. Finally, we extended the method to trace gases analysed at other wavelengths and to the determination of the near-surface aerosol extinction.

The rapid method is based on the fact that for low elevation angles, the sensitivity of MAX-DOAS observations is high only for the layers close to the surface. For an elevation angle of $1^{\circ}$ as used in this study, the altitude range, for which the measurement is sensitive for, is typically below $200 \mathrm{~m}$ (the so-called probed altitude range). Another important aspect of the rapid MAX-DOAS method is that the effective light path length can be determined from the measured absorption of the oxygen dimer $\mathrm{O}_{4}$. Using this derived effective light path length, the trace gas dSCD can be transferred into average trace gas VMRs or surface extinction, which is representative for the probed altitude range corresponding to the atmospheric visibility of that measurement. Since the vertical profile shapes of $\mathrm{O}_{4}$ and the other trace gases differ, correction factors have to be calculated and applied (Sinreich et al., 2013). Because these correction factors depend on the trace gas and aerosol profiles, we calculate mean values, as well as maximum and minimum values of the correction factors for various presumed combinations of trace gas and aerosol profiles as function of the $\mathrm{O}_{4} \mathrm{dAMF}$ by RTM. We provide extended tables of these correction factors for different trace gases $\left(\mathrm{NO}_{2}\right.$ analysis at $360 \mathrm{~nm}, \mathrm{HCHO}$ analysis at $340 \mathrm{~nm}$, $\mathrm{SO}_{2}$ analysis at $310 \mathrm{~nm}$ ) and a large variety of combinations of SZA and RAA (see Supplement). These correction factors (and the respective differences between minima and maxima) are provided as function of the $\mathrm{O}_{4} \mathrm{dAMF}$ retrieved at $360 \mathrm{~nm}$ and can be used for (future) measurements by other groups using the same method. Based on RTM we estimate the typical uncertainty of the retrieved trace gas VMRs to $20 \%$ to $30 \%$ (depending on the atmospheric visibility and the selected trace gas). Here it should be noted that in the presence of strong horizontal and/or vertical gradients, the uncertainties might be substantially larger.

As another important result of our study, we found a clear relationship between the near-surface aerosol extinction and the $\mathrm{O}_{4} \mathrm{dAMF}$ for the $1^{\circ}$ elevation angle. This indicates that the average aerosol extinction close to the surface can also be derived from the rapid MAX-DOAS method. Interestingly, the uncertainties of the retrieved surface aerosol extinction is usually smaller (typically about $15 \%$ ) than for the trace gas VMR, because only one inversion step is needed.

We applied the new method to MAX-DOAS measurements made in summer 2012 close to the city of Hefei. For that purpose we used a newly developed MAX-DOAS instrument (GM-DOAS), which can flexibly scan the atmosphere in two dimensions. For this study the GM-DOAS instrument made rapid measurements at $1^{\circ}$ elevation and four azimuth angles (sequentially pointing to $0^{\circ}, 90^{\circ}, 130^{\circ}$, and $170^{\circ}$ ). In addition, spectra were taken at $90^{\circ}$ elevation, which served as Fraunhofer reference spectra. Besides $\mathrm{O}_{4}$, dSCDs of $\mathrm{NO}_{2}$, $\mathrm{SO}_{2}$, and $\mathrm{HCHO}$ were also analysed from the GM-DOAS measurements. Since the wavelength ranges of the $\mathrm{SO}_{2}$ analysis $(310 \mathrm{~nm})$ and $\mathrm{HCHO}$ analysis $(340 \mathrm{~nm})$ differ from those of the $\mathrm{O}_{4}$ and $\mathrm{NO}_{2}$ analyses $(360 \mathrm{~nm})$, the effective light path length had to be extrapolated from $360 \mathrm{~nm}$ to $340 \mathrm{~nm}$ and $310 \mathrm{~nm}$. This relationship between the light path lengths at the different wavelengths was established by RTM for 60 typical aerosol scenarios and various combinations of SZAs and RAAs. Second-order polynomial fits were constructed to extrapolate the light path lengths to $310 \mathrm{~nm}$ and $340 \mathrm{~nm}$ to accurately calculate the light path lengths for the determination of VMRs of $\mathrm{SO}_{2}$ and $\mathrm{HCHO}$.

We measured $\mathrm{NO}_{2}, \mathrm{SO}_{2}$, and $\mathrm{HCHO}$ VMRs and their horizontal distribution in the boundary layer near the city of Hefei in China. To verify the reliability of the rapid MAXDOAS method, the VMRs were compared with those from LP-DOAS. The results of the two techniques agree well. The squares of the correlation coefficients for $\mathrm{NO}_{2}, \mathrm{SO}_{2}$, and $\mathrm{HCHO}$ were $0.92,0.85$, and 0.60 , respectively. Usually the results for the four azimuth angles were found to be very similar. However, in some cases, significant differences also occurred, which indicate horizontal gradients of the trace gas concentrations close to the surface at the experiment site. Results for $\mathrm{NO}_{2} \mathrm{VMR}, \mathrm{SO}_{2} \mathrm{VMR}$, and surface aerosol extinction showed very similar spatial-temporal variation indicating common sources. Interestingly, for the day with the strongest difference between the different azimuth angles, the strongest temporal variations of the trace gas VMRs were also found in the LP-DOAS measurements.

We also determined the aerosol extinction close to the surface from the rapid MAX-DOAS method. The results from MAX-DOAS agree well with the results (at $550 \mathrm{~nm}$ ) derived from forward-scattering visibility meters.

In summary, the novel analysis technique together with the newly developed 2-D MAX-DOAS instrument can rapidly monitor the horizontal distribution of average trace gases 
VMR and aerosol extinction in the boundary layer. The results provide important information for the analysis of emission sources, transport, and atmospheric chemical reactions of trace gases.

\section{The Supplement related to this article is available online at doi:10.5194/amt-7-1663-2014-supplement.}

Acknowledgements. This work was supported by the National High Technology Research and Development Program of China (Grant No.: 2014AA06A508 and 2014AA06A511), the Scientific and Technological Project of Anhui province(Grant No.: 1301022083), the Special Project of Environmental Nonprofit Industry Research, China (Grant No.: 201109007) and the National Natural Science Foundation of China (Grant No.: 41275038). We are very thankful to Rainer Volkamer and Roman Sinreich for their feedback to our study and fruitful discussions.

Edited by: J. Stutz

\section{References}

Bobrowski, N., Honninger, G., Galle, B., and Platt, U.: Detection of bromine monoxide in a volcanic plume, Nature, 423, 273-276, 2003.

Bogumil, K., Orphal, J., Homann, T., Voigt, S., Spietz, P., Fleischmann, O. C., Vogel, A., Hartmann, M., Kromminga, H., Bovensmann, H., Frerick, J., and Burrows, J. P.: Measurements of molecular absorption spectra with the SCIAMACHY preflight model: instrument characterization and reference data for atmospheric remote-sensing in the $230-2380 \mathrm{~nm}$ region, J. Photoch. Photobio. A, 157, 167-184, 2003.

Bovensmann, H., Burrows, J. P., Buchwitz, M., Frerick, J., Noël, S., Rozanov, V. V., Chance,K. V., and Goede, A. H. P.: SCIAMACHY - mission objectives and measurement modes, J. Atmos. Sci., 56, 127-150, 1999.

Brühl, C. and Crutzen, P. J.: MPIC two-dimensional model In the atmospheric effects of stratospheric aircraft, NASA Ref. Publ., 1292, 103-104, 1993.

Burrows, J. P., Weber, M., Buchwitz, M., Rozanov, V. V., LadstätterWeißenmayer, A., Richter, A., DeBeek, R., Hoogen, R., Brmstedt, K., and Eichmann, K. U.: The global ozone monitoring experiment (GOME): mission concept and first scientific results, J. Atmos. Sci., 56, 151-175, 1999.

Burrows, J. P., Platt, U., Borrell, P. (Eds.): The Remote Sensing of Tropospheric Composition from Space, Springer, available at: http://www.ppmborrell.co.uk/p\&pmb/publications/ RemoteSensingBook/ (last access: 20 May 2014), 2011.

Clémer, K., Fayt, C., Hendrick, F., Hermans, C., Pinardi, G., Van Roozendael, M.: The simultaneous retrieval of tropospheric aerosol extinction and $\mathrm{NO}_{2}$ vertical profiles from MAXDOAS measurements in Beijing, in: Proceedings of the 8th International Symposium on Tropospheric Profiling, ISBN 978-90-6960-2332, Delft, The Netherlands, 19-23 October 2009, 2009.

Clémer, K., Van Roozendael, M., Fayt, C., Hendrick, F., Hermans, C., Pinardi, G., Spurr, R., Wang, P., and De Mazière, M.: Multiple wavelength retrieval of tropospheric aerosol optical proper- ties from MAXDOAS measurements in Beijing, Atmos. Meas. Tech., 3, 863-878, doi:10.5194/amt-3-863-2010, 2010.

Crutzen, P. J.: The role of $\mathrm{NO}$ and $\mathrm{NO}_{2}$ in the chemistry of the troposphere and stratosphere, Annu. Rev. Earth Planet, Sci., 7, 443-472, 1979.

De Smedt, I., Stavrakou, T., Müller, J. F., Van Der A, R. J., and Van Roozendael, M.: Trend detection in satellite observations of formaldehyde tropospheric columns, Geophys. Res. Lett., 37, L18808, doi:10.1029/2010GL044245, 2010.

Environmental Protection Agency: A Summary of the Emissions Characterization and Noncancer Respiratory Effects of Wood Smoke, EPA-453/R-93-036, available at: http://burningissues. org/table2.htm (last access: 20 May 2014), 1993.

Environmental Protection Agency: National air quality and emissions trends report 1998, Rep. EPA 454/R-00-003, 1998.

Eskes, H. J. and Boersma, K. F.: Averaging kernels for DOAS totalcolumn satellite retrievals, Atmos. Chem. Phys., 3, 1285-1291, doi:10.5194/acp-3-1285-2003, 2003.

Fayt, C. and van Roozendael, M.: WinDOAS 2.1 Software User Manual, IASB/BIRA, available at: http://www.oma. be/GOME/GOMEBrO/WinDOAS-SUM-210b.pdf (last access: 20 May 2014), 2009.

Frieß, U., Monks, P. S., Remedios, J. J., Rozanov, A., Sinreich R., Wagner T., and Platt, U.: MAX-DOAS $\mathrm{O}_{4}$ measurements: A new technique to derive information on atmospheric aerosols: 2. Modeling studies, J. Geophys. Res., 111, D14203, doi:10.1029/2005JD006618, 2006.

Frieß, U., Sihler, H., and Sander, R.: The vertical distribution of $\mathrm{BrO}$ and aerosols in the Arctic: Measurements by active and passive differential optical absorption spectroscopy, J. Geophys. Res., 116, D00R04, doi:10.1029/2011JD015938, 2011.

Frins, E., Bobrowski, N., Platt, U., and Wagner, T.: Tomographic MAX-DOAS observations of sun-illuminated targets: a new technique providing well defined absorption paths in the boundary layer, Appl. Opt., 45, 6227-6240, 2006.

Frins, E., Platt, U., and Wagner, T.: High spatial resolution measurements of $\mathrm{NO}_{2}$ applying Topographic Target Light scatteringDifferential Optical Absorption Spectroscopy (ToTaL-DOAS), Atmos. Chem. Phys., 8, 7595-7601, doi:10.5194/acp-8-75952008, 2008.

Grainger, J. F. and Ring, J.: Anomalous Fraunhofer line profiles, Nature, 193, p. 762, doi:10.1038/193762a0, 1962.

Greenblatt, G. D., Orlando, J. J., Burkholder, J. B., and Ravishankara, A. R.: Absorption measurements of oxygen between 330 and 1140 nm, J. Geophys. Res., 95, 18577-18582, 1990.

Heckel, A., Richter, A., Tarsu, T., Wittrock, F., Hak, C., Pundt, I., Junkermann, W., and Burrows, J. P.: MAX-DOAS measurements of formaldehyde in the Po-Valley, Atmos. Chem. Phys., 5, 909918, doi:10.5194/acp-5-909-2005, 2005.

Hellén, H., Hakola, H., Reissell, A., and Ruuskanen, T. M.: Carbonyl compounds in boreal coniferous forest air in Hyytiälä, Southern Finland, Atmos. Chem. Phys., 4, 1771-1780, doi:10.5194/acp-4-1771-2004, 2004.

Hess, M., Koepke, P., and Schult, I.: Optical Properties of Aerosols and Clouds: The Software Package OPAC, available at: http://ether.ipsl.jussieu.fr/etherTypo/?id=1058 (last access: 20 May 2014), 79, 5, May 1998. 
Ho, K. F., Lee, S. C., Louie, P. K. K., and Zou, S. C.: Seasonal variation of carbonyl compound concentrations in urban area of Hong Kong, Atmos. Environ., 36, 1259-1265, 2002.

Hönninger, G., von Friedeburg, C., and Platt, U.: Multi axis differential optical absorption spectroscopy (MAX-DOAS), Atmos. Chem. Phys., 4, 231-254, doi:10.5194/acp-4-231-2004, 2004.

Irie, H., Takashima, H., Kanaya, Y., Boersma, K. F., Gast, L., Wittrock, F., Brunner, D., Zhou, Y., and Van Roozendael, M.: Eightcomponent retrievals from ground-based MAX-DOAS observations, Atmos. Meas. Tech., 4, 1027-1044, doi:10.5194/amt-41027-2011, 2011.

Johansson, M., Galle, B., Yu, T., Tang, L., Chen, D., Li, H., Li, J. X., and Zhang, Y., Quantification of total emission of air pollutants from Beijing using mobile mini-DOAS, Atmos. Environ., 42, 6926-6933, 2008.

Johansson, M., Rivera, C., de Foy, B., Lei, W., Song, J., Zhang, Y., Galle, B., and Molina, L.: Mobile mini-DOAS measurement of the outflow of $\mathrm{NO}_{2}$ and $\mathrm{HCHO}$ from Mexico City, Atmos. Chem. Phys., 9, 5647-5653, doi:10.5194/acp-9-5647-2009, 2009.

Kraus, S.: DOASIS, A Framework Design for DOAS, PhDthesis, University of IMannheim, available at: http://hci.iwr. uni-heidelberg.de/publications/dip/2006/Kraus_hD2006.pdf (last access: 20 May 2014), 2006.

Li, X., Brauers, T., Shao, M., Garland, R. M., Wagner, T., Deutschmann, T., and Wahner, A.: MAX-DOAS measurements in southern China: retrieval of aerosol extinctions and validation using ground-based in-situ data, Atmos. Chem. Phys., 10, 20792089, doi:10.5194/acp-10-2079-2010, 2010.

Li, X., Brauers, T., Hofzumahaus, A., Lu, K., Li, Y. P., Shao, M., Wagner, T., and Wahner, A.: MAX-DOAS measurements of $\mathrm{NO}_{2}, \mathrm{HCHO}$ and $\mathrm{CHOCHO}$ at a rural site in Southern China, Atmos. Chem. Phys., 13, 2133-2151, doi:10.5194/acp-13-21332013, 2013.

Lurmann, F. W. and Main, H. H.: Analysis of the ambient VOC data collected in the Southern California Air Quality Study, Final Report, ARB Contract NO.A832-130, California Air Resources Board, Scaramento, CA, USA, 1992.

Martin, R. V., Chance, K., Jacob, D. J., Kurosu, T. P., Spurr, R. J. D., Bucsela, E., Gleason, J. F., Palmer, P. I., Bey, I., Fiore, A. M., Li, Q., Yantosca, R. M., and Koelemeijer, R. B. A.: An Improved Retrieval of Tropospheric Nitrogen Dioxide from GOME, J. Geophys. Res., 107, 4437, doi:10.1029/2001JD001027, 2002.

Meller, R. and Moortgat, G. K.: Temperature dependence of the absorption cross sections of formaldehyde between 223 and 323 $\mathrm{K}$ in the wavelength range $225-375 \mathrm{~nm}$, J. Geophys. Res., 105, 7089-7101, 2000.

Nebuloni, R.: Empirical relationships between extinction coefficient and visibility in fog, Appl. Opt., 44, 3795-3804, doi:10.1364/AO.44.003795, 2005.

Pikelnaya, O., Hurlock, S. C., Trick, S., and Stutz, J.: Intercomparison of multiaxis and long-path optical absorption spectroscopy measurements in the marine boundary layer, J. Geophys. Res., 112, D10S01, doi:10.1029/2006JD007727, 2007.

Platt, U. and Stutz, J.: Differential Optical Absorption Spectroscopy, Springer-Verlag Heidelberg, Berlin, 229-375, 2008.

Qin, M., Xie, P. H., Liu, W. Q., Li, A., Dou, K., Fang, W., Liu, J. G., and Zhang, W. J.: Observation of atmospheric nitrous acid with DOAS in Beijing, China, J. Environ. Sci., 18, 69-75, 2006.
Richter, A. and Wagner, T.: The Use of UV, Visible and Near IR Solar Back Scattered Radiation to Determine Trace Gases, in: The Remote Sensing of Tropospheric Composition from Space, edited by: Burrows, J. P., Platt, U., and Borrell, P., ISBN 9783-642-14790-6, doi:10.1007/978-3-642-14791-3, Springer, Heidelberg, 67-122, 2011.

Rozanov, A., Rozanov, V., Buchwitz, M., Kokhanovsky, A., and Burrows, J.: SCIATRAN 2.0 - A new radiative transfer model for geophysical applications in the $175-2400 \mathrm{~nm}$ spectral region, in: Atmospheric Remote Sensing: Earth's Surface, Troposphere, Stratosphere and Mesosphere - I, edited by: Burrows, J. and Eichmann, K., 36 of Advances in Space Research, 1015-1019, 2005.

Seinfeld, J. H. and Pandis, S. N.: Atmospheric Chemistry and Physics - From Air Pollution to Climate Change, John Wiley, New York, 1998.

Sinreich, R., Volkamer, R., Filsinger, F., Frieß, U., Kern, C., Platt, U., Sebastián, O., and Wagner, T.: MAX-DOAS detection of glyoxal during ICARTT 2004, Atmos. Chem. Phys., 7, 1293-1303, doi:10.5194/acp-7-1293-2007, 2007.

Sinreich, R., Merten, A., Molina, L., and Volkamer, R.: Parameterizing radiative transfer to convert MAX-DOAS dSCDs into near-surface box-averaged mixing ratios, Atmos. Meas. Tech., 6, 1521-1532, doi:10.5194/amt-6-1521-2013, 2013.

Smith, S. J., van Aardenne, J., Klimont, Z., Andres, R. J., Volke, A., and Delgado Arias, S.: Anthropogenic sulfur dioxide emissions: 1850-2005, Atmos. Chem. Phys., 11, 1101-1116, doi:10.5194/acp-11-1101-2011, 2011.

Solomon, S., Schmeltekopf, A. L., and Sanders, R. W.: On the interpretation of zenith sky absorption measurements, J. Geophys. Res., 92, 8311-8319, 1987.

Thalman, R. and Volkamer, R.: Temperature dependent absorption cross-sections of $\mathrm{O}_{2}-\mathrm{O}_{2}$ collision pairs between 340 and $630 \mathrm{~nm}$ and at atmospherically relevant pressure, Phys. Chem. Chem. Phys., 15, 15371-15381, doi:10.1039/c3cp50968k, 2013.

Theys, N., Van Roozendael, M., Hendrick, F., Fayt, C., Hermans, C., Baray, J.-L., Goutail, F., Pommereau, J.-P., and De Maziere, M.: Retrieval of stratospheric and tropospheric BrO columns from multi-axis DOAS measurements at Reunion Island, Atmos. Chem. Phys., 7, 4733-4749, 2007,

http://www.atmos-chem-phys.net/7/4733/2007/.

Vandaele, A. C., Hermans, C., Simon, P. C., Carleer, M., Colin, R., Fally, S., Mérienne, M.-F., Jenouvrier, A., and Coquart, B.: Measurements of the $\mathrm{NO}_{2}$ absorption cross section from $42000 \mathrm{~cm}^{-1}$ to $10000 \mathrm{~cm}^{-1}(238-1000 \mathrm{~nm})$ at $220 \mathrm{~K}$ and $294 \mathrm{~K}$, J. Quant. Spectrosc. Ra., 59, 171-184, 1998.

Vlemmix, T., Piters, A. J. M., Stammes, P., Wang, P., and Levelt, P. F.: Retrieval of tropospheric $\mathrm{NO}_{2}$ using the MAX-DOAS method combined with relative intensity measurements for aerosol correction, Atmos. Meas. Tech., 3, 1287-1305, doi:10.5194/amt-31287-2010, 2010.

Vlemmix, T., Piters, A. J. M., Berkhout, A. J. C., Gast, L. F. L., Wang, P., and Levelt, P. F.: Ability of the MAX-DOAS method to derive profile information for $\mathrm{NO}_{2}$ : can the boundary layer and free troposphere be separated?, Atmos. Meas. Tech., 4, 26592684, doi:10.5194/amt-4-2659-2011, 2011.

Wagner, T., von Friedeburg, C., Wenig, M., Otten, C., and Platt, U.: UV/vis observations of atmospheric O4 absorptions using direct moon light and zenith scattered sunlight under 
clear and cloudy sky conditions, J. Geophys. Res., 107, 4424, doi:10.1029/2001JD001026, 2002.

Wagner, T., Beirle, S., Deutschmann, T., Eigemeier, E., Frankenberg, C., Grzegorski, M., Liu, C., Marbach, T., Platt, U., and Penning de Vries, M.: Monitoring of atmospheric trace gases, clouds, aerosols and surface properties from UV/vis/NIR satellite instruments, J. Opt. A: Pure Appl. Opt., 10, 104019, doi:10.1088/14644258/10/10/104019, 2008.

Wagner, T., Beirle, S., and Deutschmann, T.: Three-dimensional simulation of the Ring effect in observations of scattered sun light using Monte Carlo radiative transfer models, Atmos. Meas. Tech., 2, 113-124, doi:10.5194/amt-2-113-2009, 2009.

Wagner, T., Ibrahim, O., Shaiganfar, R., and Platt, U.: Mobile MAX-DOAS observations of tropospheric trace gases, Atmos. Meas. Tech., 3, 129-140, doi:10.5194/amt-3-129-2010, 2010.

Wagner, T., Beirle, S., Brauers, T., Deutschmann, T., Frieß, U., Hak, C., Halla, J. D., Heue, K. P., Junkermann, W., Li, X., Platt, U., and Pundt-Gruber, I.: Inversion of tropospheric profiles of aerosol extinction and $\mathrm{HCHO}$ and $\mathrm{NO}_{2}$ mixing ratios from MAX-DOAS observations in Milano during the summer of 2003 and comparison with independent data sets, Atmos. Meas. Tech., 4, 2685-2715, doi:10.5194/amt-4-2685-2011, 2011.
Wang, Y., Li, A., and Xie, P. H.: Measurements of $\mathrm{NO}_{2}$ mixing ratios with topographic target light scattering-differential optical absorption spectroscopy system and comparisons to point monitoring technique, Chin. Phys. B, 11, 114211, doi:10.1088/16741056/21/11/114211, 2012.

Wittrock, F., Oetjen, H., Richter, A., Fietkau, S., Medeke, T., Rozanov, A., and Burrows, J. P.: MAX-DOAS measurements of atmospheric trace gases in Ny-Ålesund - Radiative transfer studies and their application, Atmos. Chem. Phys., 4, 955-966, doi:10.5194/acp-4-955-2004, 2004.

Wu, F. C., Xie, P. H., Li, A., Chan, K. L., Hartl, A., Wang, Y., Si, F. Q., Zeng, Y., Qin, M., Xu, J., Liu, J. G., Liu, W. Q., and Wenig, M.: Observations of $\mathrm{SO}_{2} 2$ by mobile DOAS in the Guangzhou eastern area during the Asian Games 2010, Atmos. Meas. Tech., 6, 2277-2292, doi:10.5194/amt-6-2277-2013, 2013.

Yilmaz, S.: Retrieval of Atmospheric Aerosol and Trace Gas Vertical Profiles using Multi-Axis Differential Optical Absorption Spectroscopy, Dissertation submitted to the Combined Faculties for the Natural Sciences and for Mathematics of the RupertoCarola University of Heidelberg, Germany for the degree of Doctor of Natural Sciences, 2012. 